Int. J. Dev. Biol. 57: 689-706 (2013)

doi: $10.1387 / \mathrm{ijdb} .130148 \mathrm{am}$

\title{
Developmental control of cortico-cerebral astrogenesis
}

\author{
ANTONELLO MALLAMACI* \\ SISSA, Trieste, Italy
}

\begin{abstract}
A remarkable body of research over the last 15 years has been aimed at disentangling the cellular and molecular mechanisms which regulate murine cortico-cerebral astrogenesis. This research effort has allowed the reconstruction of the actual sizing of this process, as well as a better definition of its temporal, spatial and clonal articulation. Moreover, these investigations have shed substantial light on the cardinal molecular mechanisms governing the transition from pallial neuronogenesis to astrogenesis, as well as subsequent progress of the latter. It has turned out that proper temporal articulation of astrogenesis relies on a plethora of tightly interlaced mechanisms, which synergistically dampen astrogenesis prior to birth and promote it during peri- and postnatal life. The aim of this review is to provide a comprehensive and organic synthesis of these mechanisms, as well as a critical evaluation of their specific relevance to proper articulation of cerebral cortex astrogenesis in time and space.
\end{abstract}

KEY WORDS: cerebral cortex, astrocyte, development, molecular mechanism, chromatin

\section{Introduction}

Albeit less numerous than reported in old literature (Hilgetag and Barbas, 2009), astrocytes form a remarkable fraction of the cortico-cerebral neural complement. Non-neuronal cells numbers are an approximately linear function of brain mass, which conversely correlates with neuronal numbers according to a power law (the scale factor, depending on the CNS district and the genus the animal belongs to, equals 1.7 and 1.1 circa, in rodents and primates cerebral cortex, respectively) (Herculano-Houzel, 2012). Thus, non-neuronal cells are $47 \%$ and $79 \%$ of total cortico-cerebral cells, in mice and humans, respectively (Azevedo et al., 2009; Herculano-Houzel et al., 2011), resulting less abundant in grey compared to white matter (in humans $58 \%$ vs $94 \%$, respectively (Azevedo et al., 2009)). Astrocytes - as documented in the rodent neocortex (Irintchev, 2004) - amount to slightly less than half of these non-neuronal cells.

Astrocytes play a large variety of roles, in cortico-cerebral development, physiology and pathology (Wang and Bordey, 2008). They shape the morphology of neuronal dendrites (Ballas et al., 2009; Jacobs et al., 2010) and assist migration of some neuronal progenitors (Kaneko et al., 2010). They contribute to genesis and function of the blood-brain barrier (Tao-Cheng et al., 1987; Abbott et al., 2006; Alvarez et al., 2011; Bozoyan et al., 2012), provide structural and metabolic support to neurons (Allen and Barres, 2009; Bélanger et al., 2011; Prebil et al., 2011), and modulate synaptic transmission and information processing (Nedergaard et al., 2003; Eroglu and Barres, 2010; Sasaki et al., 2011; Min and Nevian, 2012). Finally, they react to pathological conditions, by upregulating specific gene products (intermediate filament glial librillary acidic protein (Gfap) and inhibitory extracellular matrix (ECM) proteins among them), and demarcate the damaged site from surrounding tissue with an ECM-rich scar, poorly permissive for axonal regeneration (Silver and Miller, 2004; Schachtrup et al., 2010, 2011).

\section{Spatio-temporal and clonal architecture of the cortico- cerebral astrogenic compartment}

Like elsewhere in CNS, even within the developing cerebral cortex astrocytes are mainly generated after neurons and before oligodendrocytes. Classical birthdating experiments showed that mouse astrogenesis initiates in the last third of the prenatal neuronogenic window, at around embryonic day 15 (E15). Astrocyte birthrates arise abruptly after neuronogenesis completion, peaking around postnatal day 3 (P3) (Ge et al., 2012). Then, they smoothly decrease. Consistently, Gfap ${ }^{+}$astroglial elements, just detectable around $\mathrm{E} 16$ and still rare at birth $(<2.0 \%)$, double every $3-4$ days in the first postnatal week (Qian et al., 2000), and reach their ab-

\footnotetext{
Abbreviations used in this paper: BS, binding site; ChIP, chromatin immunoprecipitation; CpG, CG dinucleotide; GOF, gain of function; LOF, loss of function; RE, responsive element; NSG, neural stem cell; TF, transcription factor; TSS, transcriptional start site.
}

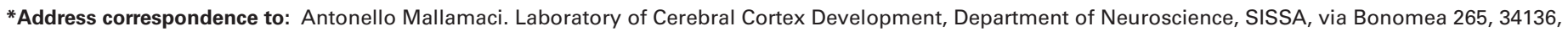
Trieste, Italy. Tel: +39-040-3787-717. Fax: +39-040-3787-702. E-mail: amallama@ sissa.it
} 
solute plateau around P21 (Bandeira et al., 2009).

Regional articulation of cortico-cerebral astrogenic matrices is relatively simple, as compared to neuronogenic and oligodendrogenic ones. Cortical neurons are generated in as many as seven tangentially distinct structures: pallium, generating the majority of glutamatergic neurons; cortical hem, cortical antihem and septum, generating pioneer glutamatergic neurons of Cajal-Retzius; medial-, lateral- and caudal ganglionic eminences (MGE, LGE and CGE), generating murine gabaergic interneurons (Guillemot, 2005). Cortico-cerebral oligodendrocytes are also born in distinct birthplaces: MGE, LGE, pallium and, apparently, thalamus (Kessaris et al., 2006). Conversely, all cortico-cerebral astrocytes exclusively derive from pallial precursors, as robustly demonstrated by cre/ loxP-mediated labelling, driven by the Emx1 promoter (Gorski et al., 2002; Tsai et al., 2012). Moreover, clonally-related astrocytes share their specific areal location. They may be found clustered along abventricular processes of remants of radial glia from which they presumably originated (Tsai et al., 2012) or adjacent to apical (i.e. abventricular) dendrites of isoclonal projection neurons (Magavi et al., 2012). That was demonstrated by injecting little amounts of cre-encoding adenoviruses into P1 Z/EG reporter mice and immunoprofiling them at P4-P28 (Tsai et al., 2012), or examining cortical development in transgenic mice in which a random and sparse subset of neural progenitors undergoes CRE/lox recombination, so permanently labeling their progeny (Magavi et al., 2012).

Concerning clonal topology of the astrogenic compartment, it was addressed in vivo, at a variety of developmental stages, by labelling periventricular neural precursors with diluted tracer-viruses (retroviruses or retroviral libraries, both selectively infecting intermitotic elements) and immunotyping the resulting clones. Depending on cases, clones were singled out on the basis of geometrical vicinity among their components (case tracer-retroviruses) or based on sharing of the same molecular tag, regardless of distance (that is the case of libraries). Precursors with mixed neuronogenic and gliogenic potencies resulted to be frequent in the early preneuronogenic forebrain (McCarthy et al., 2001), more rare (circa 10\%) in the rat E15 cortex (Walsh and Cepko, 1992, 1993; Reid et al., 1995). Glial clones containing both astrocytes and oligodendrocytes were found upon retroviral infection of the neonatal rat SVZ (at frequency of 15\%) (Levison and Goldman, 1993), but even in mouse E9.5 forebrains (albeit at frequency of only 5\%) (McCarthy etal., 2001). Finally, purely neuronal, astrocytic or oligodendrocytic clones were detected at high frequency when retroviruses were injected into the rat E15-16 cortex (Grove et al., 1993; Luskin et al., 1993) or the neonatal cortex (Luskin and McDermott, 1994). These data are consistent with a model characterized by a progressive restriction of histogenetic potencies displayed by proliferating precursors, from mixed neuronal-glial, through glial, to purely astrogenic or oligogenic. However, such progression seems to be not tightly synchronized among clones. In particular, the appearence of committed elements with restricted potencies may predate quite a lot the birth of their ultimate postmitotic progenies. Conversely, some precursors may retain their tripotency until relatively late developmental stages.

Concerning immunological identification of distinct astrogenic precursors, specific molecular markers are available, largely used in developmental studies. The A2B5+PSANCAM- antigenic profile has been specifically associated to bipotent glial progenitors, both rhombo-spinal and telencephalic, endowed with mixed astrogenic and oligogenic properties (Rao et al., 1998; Han et al., 2004; Strathmann et al., 2007). NG2+ cells may act as progenitors of oligodendrocytes and paleocortical grey matter astrocytes (Zhu et al., 2007). Cluster of differentiation 44 antigen (CD44) was described in unipotent astrogenic progenitors (Liu et al., 2004). Aldolase C (AldoC; Bachoo et al., 2004) and aldehyde dehydrogenase 1 family, member L1 (Aldh1L1; Cahoy et al., 2008) label all astrocytes, Gfap and S100b are preferentially associated to protoplasmatic and fibrous astrocytes of grey and white matter, respectively (see ref (Magavi et al., 2012)).

Concerning radial location of the different types of astrogenic precursors, the scenario is quite complex. About 13 year ago, Goetz and coll. unexpectedly found that radial glial cells, previously
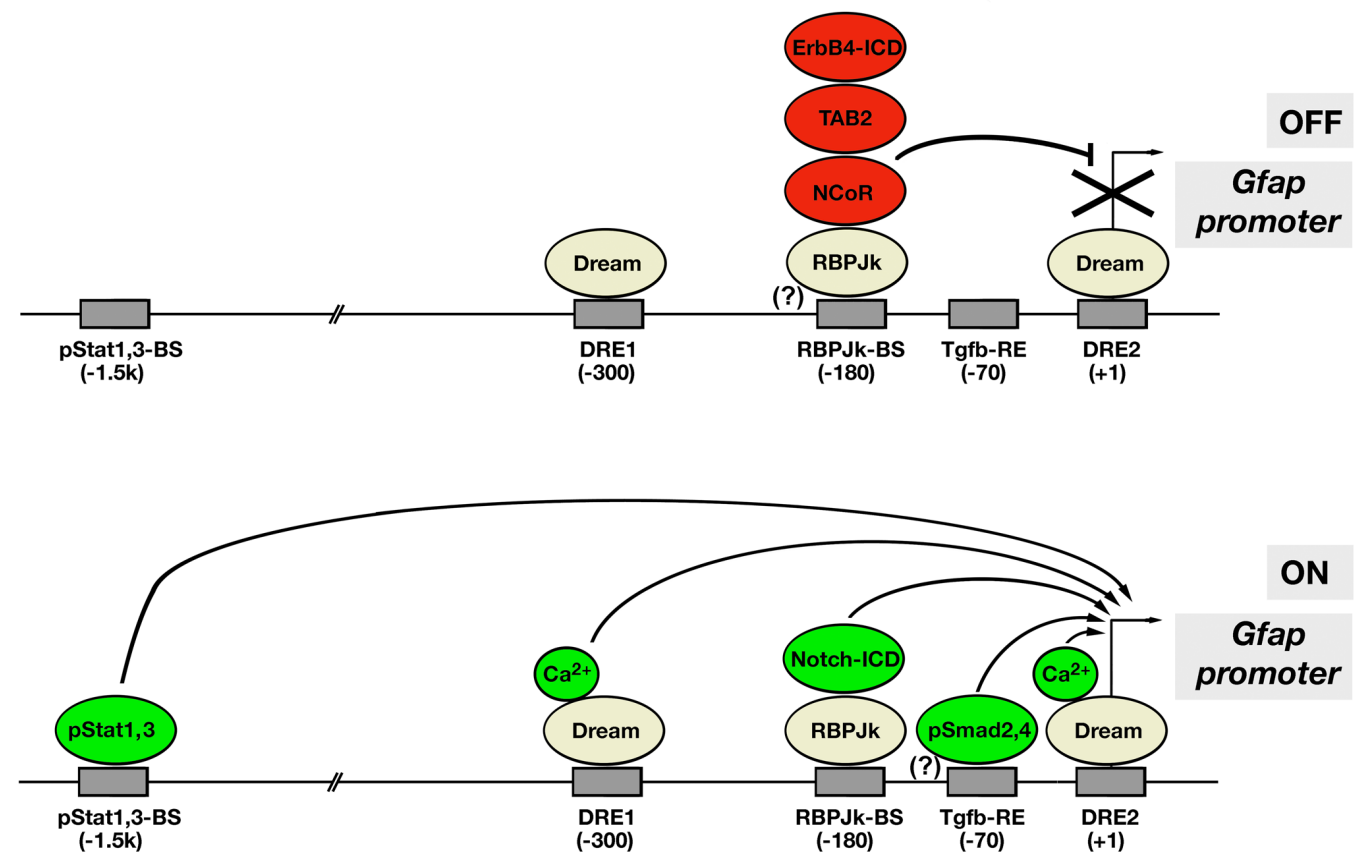

Fig. 1.Transmodulators interacting with the Gfap promoter. Shown are presumptive Gfap promoter configurations in OFF and ON states. Approximate positions of cis-active modules within the murine Gfap promoter refer to the transcriptional start site. They have been compiled on the basis of pooled mouse and rat data cited in the text, taking into account mouse/rat sequence homologies, as detected by Blat software at http:// genome.ucsc.edu. Note that physical interaction between pSmad2,4 and the Tgf 1-RE has not yet been experimentally proven. Moreover, the quaternary complex sitting on the silent promoter around -180 was simply inferred on the basis of NCOR affinity for both RBPJk and ErbB4-ICD, the latter mediated by a Tab2 bridge (see Text). 
considered as part of the glial lineage and commonly known as guiding cables for migrating neurons, also are neuronal precursors. Moreover, they showed that, only upon neurogenesis completion, radial glia shifts towards generation of astrocytes (Malatesta et al., 2000, 2003). These new concepts took quite a long time to be fully metabolized by the scientific community (Malatesta and Götz, 2013). Nowadays they have been widely accepted and early multipotent elements generating both neurons and glia are commonly supposed to coincide with a subset of prenatal radial glia (Kriegstein and Alvarez-Buylla, 2009). Moreover, it has been shown that, after completion of prenatal neuronogenesis, many radial glial cells lose their contract with the ventricular cavity and get straightly transformed in astrocytes (Noctor et al., 2004). In addition, radial glia is further believed to generate subventricular precursors (Rakic, 1988) committed to gliogenesis, bipotent or unipotent (Marshall et al., 2003), which populate the perinatal and neonatal subventricular zone and supply cerebral cortex with a substantial part of its astrocytic and oligodendrocytic complements (Zerlin et al., 1995; Kakita and Goldman, 1999; Kakita et al., 2003; Kriegstein and Alvarez-Buylla, 2009). More recently, however, it has been shown that neocortical astrocytes are actually born in different places, depending on their ultimate radial location. When EGFP-encoding plasmids were transfected into SVZ/radial glial cells of P0-P2 mice, by intraventricular DNA injection and electroporation, $16-20$ days later, $75 \%$ and $22 \%$ of labelled astrocytes were found in SVZ/white matter and layers VI/N, respectively, and only $3 \%$ in layers IV-I. This suggests that, at P0-P2, progenitors of deeper and more superficial astrocytes are near and far from the ventricle, respectively. On the other hand, injection of high titer EGFP-encoding gammaretroviruses into the cortex of P0-P2 mice was followed, 7-10 days later, by high frequency labelling of astrocytes (almost 50\%), regardless of their radial location. This means that, albeit far from the ventricle, the almost totality of layer IV-I astrocytes is generated by local proliferating progenitors (Ge et al., 2012). Actually, it was found that they derive from precursors which, still intermitotic, had left periventricular layers and undergone an almost complete astroglial differentiation (astrocyte-like dividing cells, astrolike-D cells). These cells constitute a substantial (and progressively decreasing) fraction of cortico-cerebral astrocytes (from $19 \%$ at P3, to $0.3 \%$ at P50). They give rise to repeated, symmetric divisions and supply superficial layers of grey matter with the almost totality of their astrocytic complement (Ge et al., 2012; Magavi et al., 2012).

\section{Intrinsic and extrinsic mechanisms controlling astrocyte fate choice}

Two seminal studies published about 12 year ago formally demonstrated that the switch from neuronogenesis to astrogenesis taking place in the rodent cerebral cortex around birth is the result of two key concurrent factors: the advancement of an intrinsic "developmental clock" hardwired in neural multipotent precursors (as proposed by Martin Raff and coll. in mid 80s', for optic nerve oligodendrogenesis (Raff et al., 1985; Temple and Raff, 1986)), and the activity of paracrine regulatory signals, impinging on these precursors from their surroundings.

The first study, performed by the Temple group (Qian et al., 2000), showed that isolated E10-E11 mouse cortico-cerebral stem cells, grown in Fgf2-containing basal medium, give rise to large clonal trees including both neurons and astrocytes, the latter ones generated 2- 5 generations past the former ones. That means that early cortical stem cells, even in the absence of extrinsic cues, are intrinsically programmed to switch from early neuronogenesis to late astrogliogenesis, according to a biologically plausible timetable.

The second study, performed by the Ghosh group (Morrow et al., 2001), conversely showed that proliferating neural precursors obtained by dissociation of mouse E15 cortico-cerebral tissue, give preferentially rise to neurons or astrocytes, depending on the substrate on which they are cultivated, rat E18 and P15 cortical slices, respectively. That was not due to differential survival or expansion of the committed subclones originating from these elements. Rather it reflected a differential commitment of these proliferating precursors to distinct histogenetic pathways. This commitment was induced by the surrounding micro-environment and diffusible substances were apparently responsible for it. That was suggested by the replication of these results in the presence of semipermeable barrier, interposed between the inducer tissue and the induced precursors. However, when P5 mouse precursors were assayed by this test, these cells always differentiated as astrocytes, regardless of the developmental age of the substrate supporting them. This means that, albeit the behaviour of cortical precursors is influenced by the surrounding environment, however their plasticity is limited and their histogenetic properties change irreversibly as development proceeds.

Molecular mechanisms by which intrinsic and extrinsic control of astrogenesis are implemented have been subject of an articulated dissection, still in progress. This dissection has been largely focused on factors and constraints regulating transcription of select genes, such as Gfap and $S 100 \beta$, chosen for historical and objective reasons as models of astroglia-specific transcription. Consistently with the classical findings of Temple and Ghosh, it emerged that astrocyte-specific gene expression is regulated by specific extracellular ligands secreted by surrounding cells, acting on multipotent neural precursors and modulating their histogenetic properties. Information carried by these ligands is generally conveyed to the nucleus of neural precursors via dedicated receptors and transducers. This ultimately results in differential nuclear availability of transcription factors, which, interacting with chromatin of astroglial genes, may modulate its epigenetic state and regulate its current transcription rate. Collectively, expression levels of these receptors and transducers as well as the epigenetic state of this chromatin dictate precursors ability to respond to astrogenic stimuli, namely the other key determinant of astrogenesis progression.

\section{Transactive pathways modulating astrogenesis}

It has been shown that at least 5 main trans-active pathways regulate transcription from astrocytic promoters (Gfap and $S 100 \beta$ the best characterized ones): (1) cardiotrophin 1 (Ct1)/janus kinase 2 (Jak2)/Signal transducer and activator of transcription 1 and 3 (Stat1 and Stat3), (2) Delta/Notch, (3) Neuregulin 1 (Nrg1)/v-erb-a Erythroblastic leukemia viral oncogene homolog B4 (ErbB4), (4) Transforming growth factor $\beta 1$ (Tgf $\beta 1) / T g f \beta$-receptors I and II (Tgf $\beta R$ I and TgfRII)/Small mothers against decapentaplegic homologs 2 and 4 (Smad2 and Smad4), and (5) Pituitary adenylate cyclase-activating polypeptide (Pacap)/Pituitary adenylate cyclase (Pac)/Downstream regulatory element antagonist modulator (Dream) (Fig. 1). These pathways apparently impact astrocytic promoters in direct ways. 
Some of them are further provided of "auxiliary branches", finely tuning their activity. The majority of them are functionally interconnected, according to an intricate topology.

Cardiotrophin 1-type ligands released by neurons and astrocytes, signalling via the Jak2/Stat3 axis, are the main promoters of astroglial commitment and astrocytic differentiation (He et al., 2005). Nuclear translocation of Notch-IntraCytoplasmic Domain (NotchICD), induced by Delta-type signals (from the neuronal lineage), promotes astroglial specification as well (Ge et al., 2002). Nuclear translocation of ErbB4-IntraCytoplasmic Domain (ErbB4-ICD), induced by Nrg1 (from the neuronal lineage), conversely antagonizes it (Sardi et al., 2006). Finally, further positive inputs to astrogenesis promotion come from firing of the $\mathrm{pSmad2,3}$ pathway, triggered by Tgf $\beta$ s (from both neuronal and astrocytic lineages) (Stipursky and Gomes, 2007), as well as from Pac/Dream signalling, stimulated by Pacap ligands available within the perinatal periventricular zone (Cebolla et al., 2008). An overview of these pathways follows.

\section{The Ct1 /Jak2/Stat3 cardinal pro-astrogenic pathway}

A number of IL6-related ligands, often referred to as "astrogenic cytokines" and including Cardiotrophin 1 (Ct1), Leukemia Inhibiting Factor (Lif), Ciliary Neurotrophic Factor (Cntf), Neuropoietin (Np) and Cardiotrophin-like Cytokine $(\mathrm{Clc})$, are able to strongly promote expression of astroglial genes, by acting on cortico-cerebral NSCs and astrogenic progenitors which express the corresponding receptor complex (Bonni et al., 1997; Rajan and McKay, 1998; Nakashima et al., 1999a; Ochiai et al., 2001; Uemura et al., 2002; Derouet et al., 2004; Barnabé-Heider et al., 2005). These astrogenic cytokines bind to their $\alpha$-coreceptors (including the plasmamembrane-bound ciliary neurotrophic factor receptor $\alpha, \mathrm{CntfR} \alpha$, and its secreted variant sCntfR $\alpha$ ) and trigger the heterodimerization of the two $\beta$-subunits of their main receptor, glycoprotein 130 (gp130) and Lif-receptor $\beta$ (LifR $\beta$ )". Such $\beta$-subunits contain one, plasmamembrane-proximal suppressor of high-copy PP1 protein 2 (Shp2)-binding site ( $Y x x V)$ as well as several, membrane-distal Signal transducer and activator of transcription 1 and 3 (Stat1/3)-binding sites ( $Y x \times Q)$. Ligand-induced heterodimerization of $\beta$-subunits is followed by their multiple $Y$ phosphorylation as well as by further Y-phosphorylation of the gp130/ LifRb-associated signalling mediators Stat1,3 and Shp2 (reviewed in ref (Ernst and Jenkins, 2004)). All these Y-phosphorylations are catalyzed by Janus tyrosine kinases 1 and 2 (Jak1,2), which are constitutively associated to gp130/LifRb and are phosphorylated upon gp130/LifRb stimulation. Y-phosphorylations are followed by the detachment of pStat1,3 and pShp2 from cytokine receptors (reviewed in ref (Ernst and Jenkins, 2004)). pStat1 and pStat3 homo- and heterodimers translocate into the nucleus, where they interact with chromatin (Ernst and Jenkins, 2004) and transactivate astrocyte-specific genes, such as Gfap, $\mathrm{S100} \beta$, aquaporin, etc $(\mathrm{He}$ et al., 2005). pShp2 conversely stimulates the mitogen-activated Erk kinase (Mek)/extracellular signal-regulated kinase (Erk) and the Akt cascades (Ernst and Jenkins, 2004), not directly implicated in transactivation of astroglial genes (Barnabé-Heider etal., 2005), and is involved in self-inhibition of the main astrogenic axis (Lehmann et al., 2003).

The primary role of the Ct1/Jak2/Stat3 axis in astrogenesis promotion has been thoroughly documented. mRNAs of CntfR $\alpha$ (Derouet et al., 2004), gp130, LifR $\beta$, Jak1, Stat1 and Stat3 (He et al., 2005) were found in the pallial neuroepithelium as early as at E11-12, albeit at low level. Moreover, all these genes resulted to be subsequently upregulated, peaking around birth and afterwards (Derouet et al., 2004; He et al., 2005). Knock-out of gp130 almost abolished Gfapexpression in Lif- or Cntf-treated E14.5 telencephalic precursors, as well as in the E18.5 brain (except fimbria and hippocampus) (Nakashima et al., 1999b). A similar in vivo suppression of Gfap expression was elicited by inactivation of LifR $\beta$ (Koblar et al., 1998). Moreover, pharmacological inhibition of Jak by AG490 (but not inhibition of Mek by PD98059) reduced the gliogenic effect elicited by CNTF (Barnabé-Heider et al., 2005). Finally, as for Stat3, its positive implication in stimulation of astroglial genes was proven by a variety of approaches. It was observed upon transduction of rodent telencephalic precursors with artificial alleles of Stat3, encoding for a gain-of-function version of this protein (Stat3c, constitutively dimerizing, however still requiring Lif stimulation for its transactivating properties), or encoding for dominant-negative versions of it (Stat3f, unable to get Y-phosphorylated, and Stat3d, unable to bind to DNA) (He et al., 2005)(Gu et al., 2005). Moreover, astrogenic properties of pStat3 were evident upon cre/loxP-mediated ablation of Stat3 in murine E14.5 cortico-cerebral NSCs (Cao et al., 2010), as well as after knock-down of Stat3 mediated by RNAi (Aberg et al., 2001; Barnabé-Heider et al., 2005; He et al., 2005). Interestingly, reduced astrogenesis caused by Stat3-LOF manipulations was often associated to an excess of neuronal differentiation (Gu et al., 2005; Cao et al., 2010).

Concerning real ligand(s) triggering the astrogenic cascade in the developing cerebral cortex, the situation is as follows. Cntf (Derouet et al., 2004) and Lif (Barnabé-Heider et al., 2005) are not expressed in the embryonic CNS. Np-mRNA is detectable throughout murine embryonic neuroepithelia since E11-12, disappearing around birth (Derouet et al., 2004). Clc- and Ct1-mRNAs, quite scarce at E12-14, are readily detectable by E17.5 (Uemura et al., 2002; Barnabé-Heider et al., 2005). Moreover Ct1 is specifically expressed by cortical neurons and the medium conditioned by these neurons can promote Gfap upregulation. Remarkably, this upregulation can be prevented by the addition of a neutralizing antibody against $\mathrm{C}$ t1 as well as by genetic ablation of Ct1. No prevention effects are conversely obtained by an anti-Lif neutralizing antibody or via Lif knock-out. Consistently, the Gfap ${ }^{+}$astroglial complement, as evaluated at P3, is reduced by $50-75 \%$ in Ct1-/- mutants and almost unaffected in Lif ${ }^{-/}$mutants (Barnabé-Heider et al., 2005) (except a 30\% decrease in the dentate area (Koblar et al., 1998)). All that suggests that perinatal cortical astrogenesis is mainly triggered by Ct1 released by previously born neurons, possibly with the help of Lif in some regions. Later, astrogenesis might be further promoted by Cntf released by astrocytes (Lillien et al., 1988), so self-sustaining its advancement.

\section{Auto-regulation of the Ct1/Jak2/Stat3 axis}

The Ct1/Jak2/Stat3 axis is provided of positive (Fig. 2A) and negative (Fig. 2B) regulatory loops, which finely tune its capability to sense Ct1 and Ct1-like signals and transduce them to the nucleus. These loops are crucial to proper timing of astrogenesis and appropriate regulation of the astrogenic-to-neuronogenic balance. They may be classified as follows:

\section{Modulating gp130, Jak1, Stat1 and Stat3 expression levels}

gp130, Jak1, Stat1 and Stat3 expression levels are very low in E11 cortico-cerebral precursors, they arise more and more during neuronogenesis progression and finally peak around birth. This 
upregulation is promoted by the astrogenic cytokines, through the Ct1/Jak2/Stat3 axis. This was proven, by transducing corticocerebral precursors with mutated alleles of Stat3, encoding for gain-of-function or dominant-negative versions of it (He etal., 2005). Remarkably, such upregulation is direct. In fact, evolutionarily conserved, pStat-binding sites are in the promoters af all four genes and - as proven by ChIP - they are specifically enriched in pStat3 upon Lif stimulation (He et al., 2005).

\section{Modulating Jak2 phosporylation}

Two molecular devices, triggered by $\mathrm{Ct} 1$ stimulation and encoded by suppressor of cytokine signalling gene 3 (Socs3) and Shp2, provide a negative feedback, limiting levels of phospho-Jak2 upon cytokine stimulation and so concurring to proper balance between astrogenesis and neuronogenesis.

Socs3, upregulated by Jak/Stat signalling, binds to a single, membrane-proximal Y residue of LifR $\beta$ or gp130 (Y757 of mouse gp130), upon phosphorylation of this residue which follows cytokinedependent stimulation of the receptor complex (Schmitz etal., 2000). In this way, Socs3 recruits the proteasome to the ligand-occupied receptor complex and triggers degradation of its components as well as inhibition of Jak2 phosphorylation (Krebs and Hilton, 2001). Relevance of Socs3 to proper tuning of astrogenic rates was demonstrated by adenoviral transduction of Socs3 to rat E15-17 striatal precursors, followed by exposition of these cells to Lif or Lif/Fgf2 (Cao et al., 2006). It was found that Socs3 downregulates the astroglial output elicited by cytokine stimulation, in as little as 1 day. This was associated to early upregulation of NSC markers and delayed increase of the percentage of microtubule associated protein 2-expressing (Map2+) elements originating from the culture. That reasonably reflected an inhibition of glial commitment of NSCs, which, even in the presence of gliogenic citokines, retain their identity and are consquently available for alternative histogenetic pathways (Cao et al., 2006).

The phosphorylation-dependent Shp2 tyrosine phosphatase also binds to the LifR $\beta / g p 130$ phospho-tyrosine residues which interact with Socs3, upon cytokine stimulation (Schmitz etal., 2000). Following that, Shp2 dephosphorylates the adjacent Jak2, so attenuating Jak/Stat signalling (Lehmann et al., 2003). In humans, mutations leading to constitutive activation of SHP2 cause the Noonan Syndrome (NS), which includes learning disabilities and mental retardation. In the mouse, knockdown of Shp2 in cultured cortical precursors or in the developing embryonic cortex inhibits neuronogenesis, anticipates astrogenesis and enlarges the astrocytic complement. Conversely, expression of an constitutively active Shp2 mutant causes an opposite phenotype, like it also happens in a mouse model of human NS. Thus, in normal corticogenesis, Shp2 channels early neural precursors to make neurons and not astrocytes, so contributing to postposition of astrogenesis to late gestational and early postnatal ages (Gauthier et al., 2007).

\section{Hetero-regulation of the Ct1/Jak2/Stat3 axis, by orthogonal modulatory plugins}

Several orthogonal regulatory branches converge onto the $\mathrm{Ct1/Jak2/Stat3}$ axis, finely tuning its firing rates (Fig. 3). Based on position of their entry points on this axis, these branches may be classified as follows.

\section{Regulating levels of the Ct1-receptor (gp130)}

Two heterologous players regulate gp130 expression levels, the proneural machinery and the Mek/Erk signalling machinery (Fig. 3A).

As shown by both gain- and loss-of-function experiments, Neu-
A

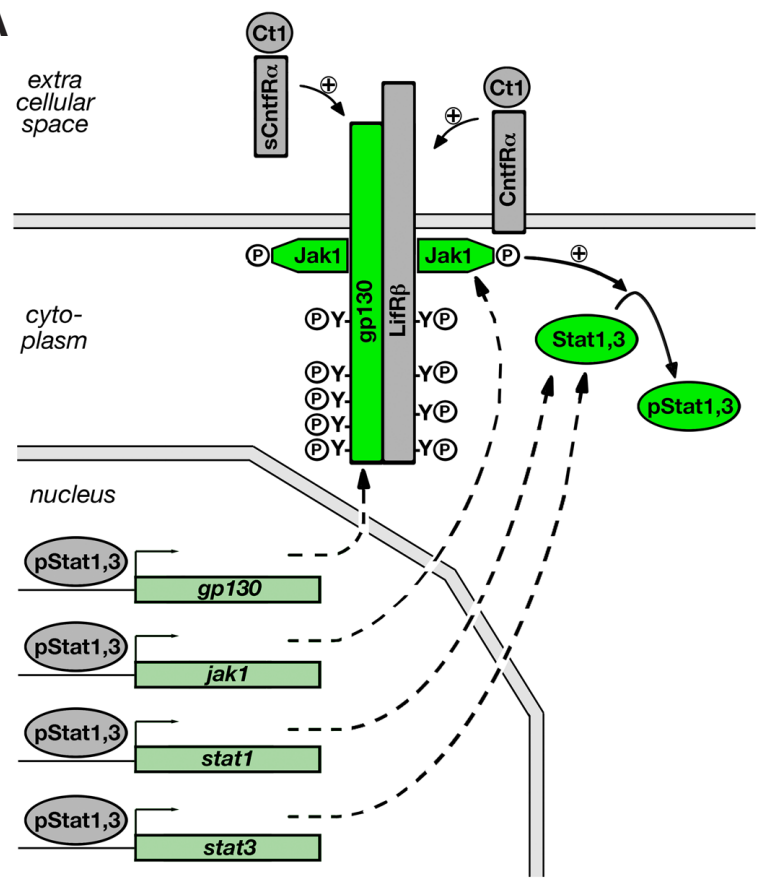

B
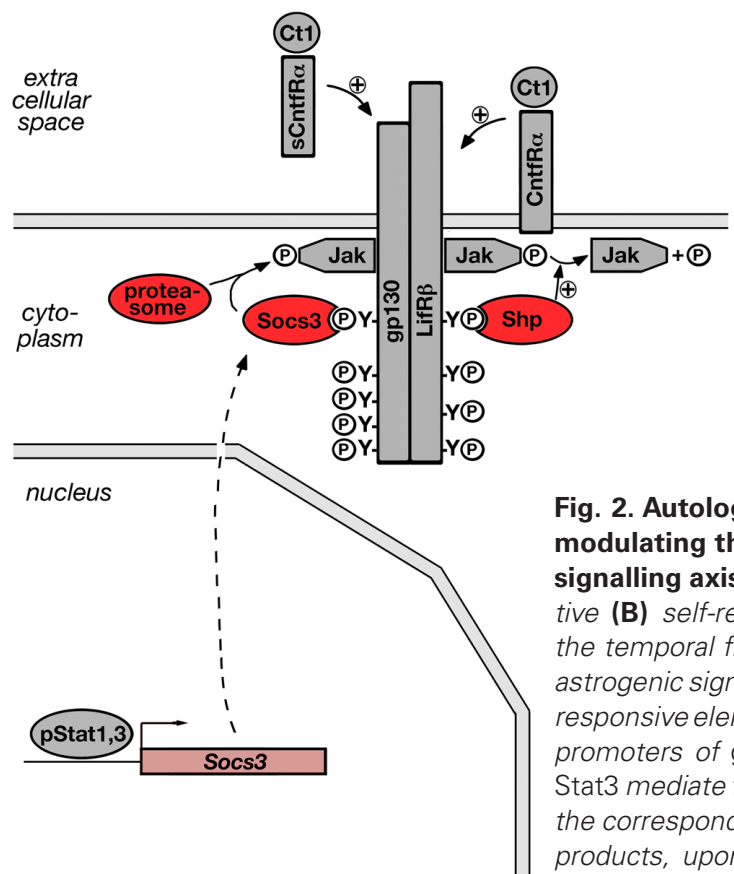

Fig. 2. Autologous regulatory loops modulating the astrogenic cytokine signalling axis. Positive (A) and negative (B) self-regulating loops shaping the temporal firing profile of the main astrogenic signalling axis. (A) pStat1,3responsive elements located within the promoters of gp130, Jak1, Stat1 and Stat3 mediate the progressive surge of the corresponding mRNAs and protein products, upon activation of this axis by Ct1-type ligands. (B) pStat1,3 also directly promote transcription of Socs3, whose protein product binds the most plasma membrane-proximal tyrosine residue of gp 130/LifRb, phosphorylated upon Ct1 signalling. From this position, Socs3 recruits the proteasome to the gp130/LifRb-bound phosphorylated Jak, so paving the way to its degradation. (B) Finally, upon Ct1 signalling, the phosphorylated, most plasma membrane-proximal tyrosine residue of gp 130/LifRb gets bound by the Shp phosphatase, which dephosphorylates the gp130/LifRß-bound phospho-Jak and so prevents further phospho-Jak-dependent, Stat1,3 activation. 
rogenin1 (Neurog1) and Neurogenin2 (Neurog2)" do repress gp130 expression (He et al., 2005). These two factors peak during the neurogenic period and so contribute to postponing astrogenesis to perinatal and postnatal phases.

Concerning the Mek/Erk axis, it has been recently shown that co-ablation of Mek1 and Mek2 in radial glial cells (RGCs), by Nestin-Cre, hGFAP-Cre or electroporated pCMV-Cre, inhibits the switch of RGCs from neuronogenesis to gliogenesis and prevents appearence of astrocyte- and oligodendrocyte-restricted progenitors. Consequently, surviving Mek1/2-deleted mice exhibit cortices almost devoid of astrocytes and oligodendroglia and undergo extensive neurodegeneration. Asimilar but less drastic phenotype follows co-ablation of Erk1 and 2. Conversely, electroporation of a constitutively active form of Mek1 (caMek1) leads to precocious activation of astrogenesis (Li et al., 2012). Remarkably, the effects of the Mek/Erk machinery on astrogenesis are largely mediated by the Ets transcription family member Etv5/Erm, which - detectable in the VZ at E14.5-E18.5 - is necessary and sufficient

A
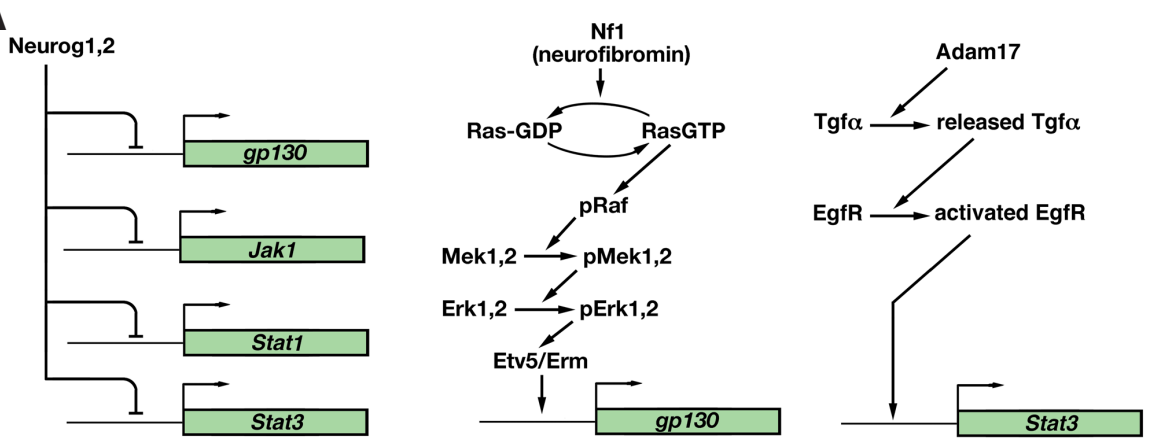

B
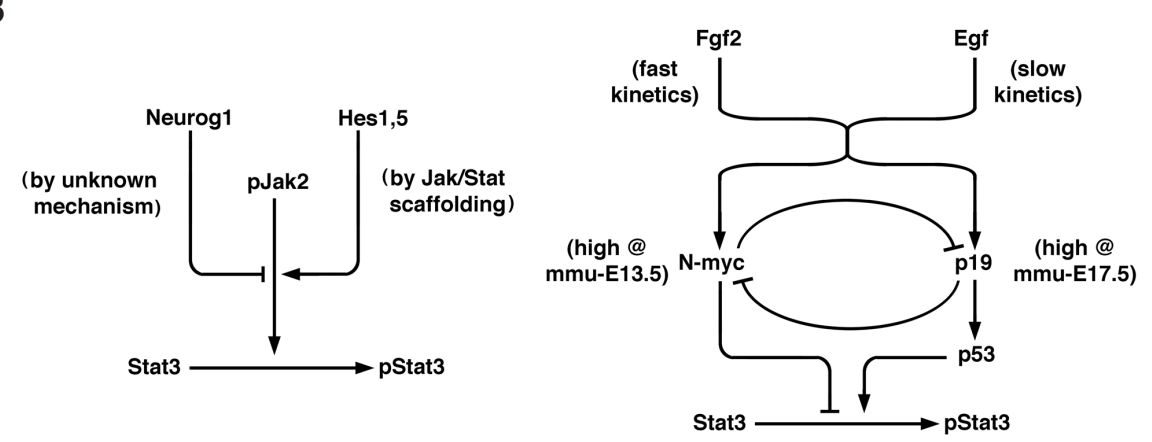

C
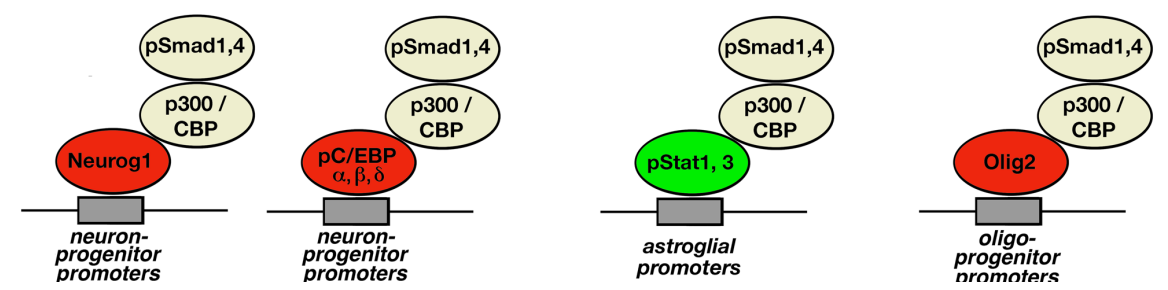

Fig. 3. Heterologous regulatory plugins modulating the astrogenic cytokine signalling axis. (A) Transcriptional regulation of genes encoding for key members of the signalling axis. Neurog 1 and 2 inhibit gp130, Jak1, Stat1 and Stat3; the Mek/Erk cascade upregulates gp130; Egf signalling promotes Stat3. (B) Modulation of Stat3 phosphorylation, by Neurog1, Hes1,5, N-myc and p19. (C) Competition among pro-neuronogenic Neurog1 and pC/EBP $\alpha u \beta u \delta$, pro-astrogenic pStat1,3, and pro-oligodendrogenic Olig2 for limited amounts of p300/CBP-pSmad1,4 heterodimeric cofactors available in neural precursors. for activation and progression of astrogenesis (Li et al., 2012). Puzzlingly, however, extracellular signals triggering astrogenic firing of the rat sarcoma (Ras)/rapidly accelerated fibrosarcoma (Raf)/Mek/Erk axis have been poorly defined. For example, Fgf2, an established stimulator of this axis (Dorey and Amaya, 2010), promotes astroglial differentiation in the absence of any gp130 upregulation (Song and Ghosh, 2004), namely a major effect of astrogenesis may be mediated by alternative pathways (Dorey and Amaya, 2010). On the other hand, Mek/Erk stimulation of astrogenesis is consistent with the capability of Nf1 to limit glioWang et al., 2012). In fact the product of Nf1, Neurofibromin1, is a Ras-GTPase that converts the GTP-bound active form of Ras to the inactive, GDP-bound form (Scheffzek et al., 1997), so that Erk pathway. Nf1 was inactivated constitutively (Dasgupta and Gutmann, 2005), limited to E12.5 radial glia and its progenies (by Brain lipid binding protein gene-driven cre (Blbp-cre)"-cre and Gfap-cre deleters) (Hegedus et al., 2007; Wang et al., 2012), as well as in postnatal SVZ B cells and their progenies (by a Nestin-creET deleter and tamoxifen administration at P26-30) (Wang et al., 2012). In all cases a dramatic increase of gliogenesis was reported. In constitutive and early embryonic $\mathrm{Nf1}$-knock-out models that was associated to a remarkable enlargement of the subventricular zone and hyperthrophy of the corpus callosum (Dasgupta and Gutmann, 2005; Hegedus et al., 2007). In postnatal knock-out models, NSC-restricted Nf1 deletion resulted in increased gliogenesis at the expense of neurogenesis (Wang et al., 2012). Remarkably, exaggerated glial commitment triggered by $\mathrm{N} f 1$ ablation could be phenocopied by constitutive overactivation of the Ras pathway (Hegedus et al., 2007), and rescued by small inhibitors of Mek/Erk signalling (Wang et al., 2012).

The key mechanism mediating astrogenic properties of the Ras/Raf/Mek/Erk axis is Mek1,2-dependent upregulation of gp130, encoding for one of the two subunits of the cardiotrophin 1-receptor. This upregulation, in fact, considerably sensitizes neural precursors to Ct1-family astrogenic cytokines. However, additional mechanisms concur to astrogenic properties of the Ras/Raf/Mek/Erk axis. First, Mek1,2 contribute to glial commitment of neural precursors by upregulating two hubs mastering this process. These are Chicken ovalbumin upstream promotertranscription factor 1 (Couptf1), which triggers key epigenetic changes propedeutic to astrogenesis, and Epidermal growth factor receptor (EgfR), which promotes expression of the key Ct-1 transducer Stat3 and makes neural precursors more responsive 
to its active pStat3 form (see below). Second, firing of this axis stimulates proliferation and selective expansion of astroglial lineage elements. This happens upon defective Nf1-dependent Ras inihibition in embryonic NSCs, resulting in increased selfrenewal of these elements and more frequent late-born Olig2+ glial progenitors originating from them (Hegedus et al., 2007). In a similar way, sustained Mek1,2 signalling forces astrocytes to keep proliferating for longer times after their generation, so further amplifying the glial output of the system in vivo (Li et al., 2012).

\section{Regulating Jak1 levels}

During the early neurogenic period, Jak1 protein levels are kept low by proneural genes (Fig. 3A), which contributes to delayed activation of astrogenesis (He et al., 2005).

\section{Modulating Stat1 and Stat3 levels}

Two main players modulate expression levels of Stat proteins, namely the proneural machinery and the Egf transduction machinery (Fig. 3A).

Downregulation of Stat1 and Stat3 by Neurog1 and Neurog2 was demonstrated by both gain- and loss-of-function approaches (He et al., 2005). It is a key mechanism preventing precocious activation of astrogenesis.

Conversely, signalling through EgfR (aka ErbB1) promotes cortico-cerebral astrogenesis. EgfR is expressed at low level in the ventricular zone of the neuronogenic pallium and, at higher and higher levels in basal proliferative layers of the developing cortex (Caric et al., 2001). Already at the end of 90's, it was reported that mice lacking EgfR suffer of delayed astrocyte development (Kornblum et al., 1998; Sibilia et al., 1998). In 1997 and 2003, two seminal papers from the Lilien group, clarified cellular and molecular modalities of EgfR-dependent regulation of astrogenesis (Burrows et al., 1997; Viti et al., 2003). In the former study, the authors found that retrovirus-mediated overexpression of EgfR, in the $\mathrm{E} 15$ rat brain or in E12/E15 organotypic cultures of rat cortex, upregulates their astrocytic output, whereas delivery of the two main EgfR ligands, Egf and Tgfa, to EgfR-wt brains of the same developmental ages does not alter astrogenic rates. These data suggest that, at both E12 and E15, EgfR levels, rather than ligand levels, limit firing of the Egf transduction pathway and, therefore, astrogenesis rates. Only starting from E18, endogenous EgfRs levels would become sufficiently high to be saturating for astrocytes generation. Further dissection of this phenotype by clonal analysis showed that the increased astrogenic output elicited by EgfR/Egf manipulations actually has a dual origin. It reflects an enhanced astroglial commitment of multipotent precursors and it is amplified by more pronounced proliferation of committed elements. Remarkably, whereas combined EgfR/Egf manipulation was required to increase astroglial commitment at E12 and E15, simple delivery of exogenous ligand was sufficient for that at E18. This suggests that minimal firing of the Egf transduction pathway necessary for astroglial commitment may be higher than that required for promotion of proliferation (Burrows et al., 1997). Consistently with results of EgfR-GOF studies, cortical explants from E17 $\mathrm{EgfR}^{-/-}$mutant mice did not react to exogenous Lif administration. They differred from wt controls, which conversely responded with a quite enhanced astrogenic output (Viti et al., 2003).

Concerning molecular mechanisms underlying EgfR promotion of astrogenesis, Egf signalling upregulates astrogenesis rates, mainly by facilitating transmission of the $\mathrm{Ct} 1$ signal through the Jak2/Stat3 axis via EgfR-dependent upregulation of Stat3 expression. In fact, retroviral transduction of EgfR into murine, wild type cortico-cerebral precursors of different developmental ages considerably increases the frequency of Stat $3^{\text {high }}$ cells (ten-fold at E11, two-fold at E16), whereas EgfR knock-out in E16 precursors grown in vitro for 4 days reduces this frequency by about $5 / 6$-fold (Viti et al., 2003). On the other hand, following retroviral transduction of Stat3 into E11.5 precursors and in the only presence of endogenous astrogenic cytokines, frequencies of pStat $3^{+}$elements and $S 100 \beta^{+}$derivatives reach plateau values (not further upregulatable by exogenous Lif stimulation), which may be elicited in Stat3-wt cells of similar age by simple administration of exogenous Lif. In other words, the upregulation of Stat3 triggered by EgfR sensitizes embryonic neural precursors to the astrogenic cytokines, sufficiently to achieve a pronounced astrogenic response, even in front of low levels of these ligands (Viti et al., 2003).

However, pro-astrocytogenic activities of EgfR signalling cannot be fully accounted for in the light of Stat3 upregulation. In fact, experimental overexpression of EgfR in early cortical precursors $(E 11-13)$ upregulates frequencies of both $\mathrm{S} 100 \beta^{+}$and $\mathrm{Gfap}^{+}$astrocytes, whereas straight Stat3 overexpression in the same cells increases S100 $\beta^{+}$cells, but not Gfap ${ }^{+}$ones. That suggests that an Egf-dependent mechanism different from Stat3 upregulation may be selectively required to activate Gfap. This mechanism cannot be Stat3 phosphorylation, as Lif stimulation elicits similar levels of pStat3 in both EgfR-GOF and Stat3-GOF early cortical precursors (E11-13). It could be something else, working in pa rallel to pStat3 or downstream of it (Viti et al., 2003). On the other side, the expansion of the Gfap $^{+}$compartment triggered by EgfR stimulation might partially have nothing to do with Gfapactivation, being alternatively due to increased proliferation of astroglially-committed progenitors (Gadient et al., 1998).

Concerning the ligand triggering the EgfR-mediated astrogenic response in vivo, it is possible that this function is early shared by Egf and transforming growth factor $\alpha(\operatorname{Tgf} \alpha)$ and subsequently played by Tgf $\alpha$ only. In fact, both ligands are expressed in the neuronogenic cortical primordium (the former throughout it, the latter confined to its lateral border) (Assimacopoulos et al., 2003), but only Tgf $\alpha$ (and no Egf at all) is detectable in postnatal periventricular precursors (Romero-Grimaldi et al., 2011). Consistently with this prediction, mice expressing reduced $\operatorname{Tgf} \alpha$ levels have a decreased number of astrocytes (Weickert and Blum, 1995). Remarkably, the activity of $A$ disintegrin and metallopeptidase domain (Adam) "sheddases" is required to make Egf/Tgf $\alpha$ ligands available in the extracellular space (Blobel, 2005), so enabling astrogenesis. Both Adam10 and Adam17 are co-expressed in the VZ of the mid-neuronogenic cortical primordium (Diez-Roux et al., 2011) as well as in periventricular precursors of postnatal cortex (Romero-Grimaldi et al., 2011). However only Adam17 seems implicated in astrogenesis promotion. In fact, Adam 17 knock-down impairs astrogenesis and its expression levels go up in damaged brain regions undergoing astrogliosis. That, conversely, does not apply to Adam10 (Romero-Grimaldi et al., 2011).

\section{Modulating Stat3 phosphorylation}

Mechanisms mediating astrogenic properties of Notch include promotion by the Delta/Notch/Hes axis of signalling through the Jak/Stat pathway. That is achieved by the Notch-effectors hairy 
enhancer of split homologs 1 and 5 (Hes1 and Hes5), which act as bridges between Jak2 and Stat3 and facilitate phosphorylation of the latter by the former (Fig. 3B) (Kamakura et al., 2004). As a consequence of that, overactivation of the Notch signalling in murine $\mathrm{E} 12$ telencephalic precursors, followed by their in vitro expansion for 9 days, leads to a considerable enhancement of their astroglial differentiation. Consistently, such enhancement is fully suppressed, when a dominant-negative form of Stat3 is introduced in these cells (Kamakura et al., 2004).

Among mechanisms by which proneural genes inhibit astrogenesis, there is Neurog1 inhibition of Lif/Ct1-induced Stat1,3 phosphorylation (Fig. 3B). Molecular details of this inhibition are poorly known. It has been suggested that such inhibition contributes to diversify the responses exhibited by both E13.5 and E17.5 murine cortical precursors to Lif/Ct1. Both precursor types undergo Jak2 phosphorylation, only the latter phosphorylates Stat3 (Sun et al., 2001). As a consequence of that, E13.5 are only neuronogenic, E17.5 are mainly astrogenic. Consistently, the cortex of mutants double knock-out for Neurog2and Mouse achaete scute homolog 1 (Mash1) has increased numbers of glial progenitors and activates astrogenesis earlier (Nieto et al., 2001).

Finally, a reciprocal regulatory loop, including Neural myelocytomatosis prooncogene ( $N$-myc) and INK4a p19 protein/alternate reading frame of the INK4a/ARF locus (p19(Arf)), regulates Stat3 phosphorylation, thus channelling Jak/Stat signalling machinery to distinct OFF and ON states (Fig. 3B). N-Myc and p19(Arf) are expressed by NSCs prevalently during the embryonic and the perinatal/postnatal phases of cortico-cerebral histogenesis, respectively. The former promotes NSC self-renewal and neuronogenesis, the latter sustains astrogenesis. Both are induced by Fgf2 and Egf, along a fast and a slow kinetics, respectively. The latter is further promoted by CNTF-dependent pStat3. N-Myc and p19(Arf) reciprocally inhibit their expression. N-Myc counteracts CTNF-dependent phosphorylation of Stat3 at Y705, p19(Arf) facilitates this phosphorylation, via p53. In this way, the N-Myc/p19(Arf) loop concurs to neatly define the functional state of the Ct1/Jak2/ Stat3 axis, OFF or ON, during the embryonic and the post-natal life, respectively (Nagao et al., 2008).

\section{Acting downstream of or in parallel with pStat3}

It was shown that in vitro cultured telencephalic precursors from E14.5 mouse embryos activate Gfap in as little as 2 days under combined Lif/Bmp2 stimulation, taking at least 2 days more in the presence of either cytokine (Nakashima et al., 1999c). Remarkably, such capability of Lif and bone morphogenetic factor 2 (Bmp2) to synergically promote astrogenesis was confirmed in E16.5 corticocerebral precursors kept under thyroid hormones (Adachi et al., 2005). Looking for molecular mechanisms underlying this phenomenon, it was found that no direct interaction occurs between the two key transducers of Lif and Bmp signalling, Stat3 and Smad1, respectively. Conversely, they are bridged by the transcriptional coactivator p300/CBP, interacting with Stat3 at its amino terminus (even in the absence of Lif/Ct1 stimulation) and with Smad1 at its carboxyl terminus (upon Bmp stimulation). This leads to the formation of a pStat3-p300/CBP-pSmad1 ternary complex, which is recruited to the Gfap promoter and mediates cooperative promotion of its transcription by Lif and Bmp2 (Fig. 3C). More generally, it accelerates induction of astrocytes from neural progenitors and amplifies the astrogenic output (Nakashima et al., 1999a). Intrigu- ingly, addition of Bmp2 alone to gp130-/-neural cultures, insensitive to Lif, elicits a moderate but reproducible activation of the Gfap promoter, suggesting that $\mathrm{pSmads}$ might also directly transactivate such promoter, independently of pStat3 (Nakashima et al., 1999c).

As reported above, the proneural factor Neurog1 inhibits astrogenesis by counteracting Stat3 phosphorylation. However, it also inhibits pStat3 activity, by competing with pStat3 for binding to p300/CBP-pSmad1 (Fig. 3C) and so diverting such heterodimer to neuron-specific promoters (Sun et al., 2001). Actually, it was shown that in cultures of rat E18 cortico-cerebral precursors, Ngn1 downregulates Gfap promoter-driven transcription, even upon administration of Cntf or Bmp. On the other hand, overexpression of either $\mathrm{p} 300 / \mathrm{CBP}$ or Smad1 significatively rescues glial differentiation from Ngn1 suppression. Moreover, both CBP/p300 and Smad1 potentiate the transcription of a Ngn1-responsive promoter (Sun et al., 2001). Interestingly, in extracts from rat E14 cerebral cortex, p300/CBP is associated with both Neurog1 and Smad1, but not with Stat3 (which - nevertheless - is expressed at high levels in these extracts). In contrast, in extracts of P3 corticocerebral SVZ, rich of astroglial precursors and not expressing Neurog 1 anymore, Stat3 is associated to p300/CBP (Sun et al., 2001). The most parsimonoius explanation of these data is that the p300/CBP-pSmad1 heterodimer may potentiate both neuronand astrocyte-specific transcriptions, by complexing Neurog1 and pStat3, respectively. However, p300/CBP-pSmad1 is available only to a limited extent, so that a competition takes place between its interactors for binding to it. This competition is intrinsically biased in favor of Neurog1. Therefore, until proneural genes are abundantly expressed, it is won by their products, so resulting in competitive silencing of astroglial transcriptions. Only after neuronogenesis completion, proneural factors disappear, so allowing astrocytespecific transcriptions to rise (Sun et al., 2001). This capability of Ngns to antagonize astroglial transcriptions might be the main mechanism underlying exaggerated generation of astrocytes, which has been recently found in cultures of pallial precursors knock-out for Pax6 (Sakayori et al., 2012), namely a direct transactivator of Neurog 1 and Neurog2 promoters (Scardigli, 2003; Blader, 2004).

An additional transcription factor set limiting pStat3 activity includes the leucin-zipper family transcription factors CCAAT/enhancer binding protein $(\mathrm{C} / \mathrm{EBP})-\alpha,-\beta$, and $-\delta$. These are expressed by E12-18 cortico-cerebral precursors, are activated by Mek/Erkdependent phosphorylation, and are necessary and sufficient to promote neuronogenesis. That was shown in vitro, transfecting E12 precursors with plasmids encoding for two distinct, dominantnegative variants of $C / E B P-\beta$ (counteracting all $C / E B P$ paralogs) or a constitutively active, phosphomimetic variant of it, and scoring their progenies 3-4 days later. This was confirmed in vivo, electroporating $\mathrm{E} 15$ brains with these constructs and analyzing them 3 days later (Ménard et al., 2002; Paquin et al., 2005). Remarkably, in addition to impairment of neuronogenesis, functional knock-down of C/EBPs also promotes Cntf-dependent astroglial differentation, suggesting that C/EBPs may normally contribute to prevent precocious activation of this process. However mechanisms mediating these phenomena are still matter of debate. The increased astroglial output obtained upon C/EBPs knock-down might simply reflect the higher fraction of neuronogenic precursors which retain the stem state upon this manipulation, so resulting available to subsequent glial differentiation (Ménard et al., 2002; Paquin et al., 2005). However, overexpression of a phospho-dead variant of C/EBP- $\beta$, 
while repressing neuronogenesis, did not affect astrogenesis at all (Paquin et al., 2005), suggesting that mechanisms mediating C/ EBP-dependent regulation of astrogenesis should at least partially differ from those impacting neuronogenesis. It was shown that C/EBP- $\beta$ is able to bind CBP/p300 (Mink et al., 1997). As such, similar to Neurogenins and Olig2 (Sun et al., 2001; Fukuda et al., 2004), it might sequester the p300/CBP-pSmad1 heterodimer (Fig. 3C), making it not available to bind pStat3 and so preventing transcription of glial genes.

Finally, it has been shown that the basic, helix-loop-helix $(\mathrm{bHLH})$ factor Olig2, implicated in cortico-cerebral gliogenesis, may also counteract the astrogliogenic activity of pStat3, in a Neurog1-like way (Fig. 3C) (Fukuda et al., 2004). Olig2 is widely expressed in the Gaba-ergic neuronal lineage as well as by oligodendroglial cells at different stages of their maturation (Cai et al., 2007). Within the astrocytic lineage, it gives rise to a transient perinatal activation wave (Cai et al., 2007; Ono et al., 2008), subsequently declines and fully disappears by P21 (Cai et al., 2007). Such Olig2 downregulation in differentiating astrocytes is fully replicated in vitro, in 4 days-old cultures of murine E14,5 telencephalic precursors, kept under Lif (Fukuda et al., 2004). Remarkably, Olig2, if overexpressed in perinatal cortical precursors, competes with pStat3 for binding to the p300/CBP-pSmad1 dimer, so antagonizing astrocytic differentiation (Fukuda et al., 2004). This mechanism might be crucial to restrict full activation of the Gfap promoter to mature astrocytes and avoid any leakage of it in the oligodendrocytic lineage. Moreover, it could help explaining some traits of the complex phenotype displayed by Olig2-/- mutants, such as reversion of Gfap and $\mathrm{S} 100 \beta$ relative expression levels in layers II-IV of neocortex (Cai et al., 2007).

\section{The anti-astrogenic Nrg1/ErbB4 pathway}

A major role in setting up the proper onset of astrogenesis is played by the ligand Neuregulin1 (Nrg1), expressed by neurons and neural precursors, and its ErbB4 receptor, transducing its signal within cortico-cerebral precursors. This was demonstrated by Sardi et al., (Sardi etal., 2006), co-manipulating the Nrg1/ErbB4 and the Ct1/Jak2/Stat3 pathways in telencephalic precursors and assaying consequences of that on the activation of astroglial genes.

Transduction of the Nrg1 signal along the "canonical" pathway starts with Nrg1 binding to ErbB receptors, inducing their hetero- or homodimerization. That results into activation of their intracellular tyrosine kinase activity and generation of docking sites for adaptor proteins, in turn activating the Raf/Mek/Erk and the phosphoinositide-3-kinase (PI3K) machineries (Mei and Xiong, 2008). Remarkably, this canonical pathway is not sufficient to control astrogenesis. Nrg1 control of astrogenesis is conversely exerted via an alternative transduction pathway, called "non canonical". In this case, binding of the Nrg1 ligand to the juxta-membrane $\alpha$ $(\mathrm{jM} \alpha)$ isoform of ErbB4 is followed by ErbB4 cleavage by Tumor necrosis factor $\alpha$ (TNF $\alpha$ )-converting enzyme (TACE), releasing a soluble extracellular peptide that contains the NRG1 binding site (ecto-ErbB4). The residual membrane-anchored fragment (ErbB4$\mathrm{CTF}$ ) is further cleaved in its transmembrane domain by presenilindependent $\gamma$-secretase, releasing the ErbB4 intracellular domain (ErbB4-ICD). As shown by two-hybrid and co-immunoprecipitation assays, ErbB4-ICD specifically binds to nuclear receptor corepressor (NCoR), via a Tgf $\beta$-activated protein kinase 1 (Tak1)-associated binding protein 2 (Tab2) bridge. Then ErbB4-ICD, being provided with a NLS, conveys the resulting trimeric complex ErbB4-ICD/Tab2/
NCoR into the nucleus, where each component of it can be found associated to the chromatin of Gfap and $S 100 \beta$ (Sardi et al., 2006). Interestingly, the ErbB4-ICD capability to drive cytoplasm-to-nucleus NCoR translocation is dominant over the opposite ability of the firing Jak/Stat axis to extrude this cofactor from nucleus. Actually, binding sites of the ternary ErbB4-ICD/Tab2/NCoR complex within Gfapand $S 100 \beta$ promoters were not mapped. It was proposed that this complex would be further connected to recombination signal binding protein for for immunoglobulin kappa $\mathrm{J}$ region (RBPJk), for which NCoR has a very high affinity, and, in such a way, it might bind to the Gfap promoter in correspondence of its RBPJk binding site (Miller and Gauthier, 2007). Remarkably, ErbB4 cleavage, its Tab2-mediated interaction with $\mathrm{NCoR}$, and nuclear translocation of the ErbB4-ICD/Tab2/NCoR complex, all do require binding of $\mathrm{Nrg} 1$ to the jMa isoform of ErbB4. The last two steps further rely on the first. Interestingly, when the "non canonical" ErbB4 pathway is overactivated in rat E14.5 telencephalic precursors in vitro, this suppresses the increase of Gfap-and $5100 \beta$-promoter-driven transcription, otherwise observable after subsequent Cntf stimulation. Conversely, no effect is exerted by ErbB4 pathway overactivation on basal Gfap- and $S 100 \beta$ - transcription levels detectable in the absence of Ctnf (Sardi et al., 2006). Consistent data were obtained after experimental manipulation of the non canonical Nrg1/ErbB4 axis in vivo. Gfap expression levels were dramatically upregulated in the E17.5 cerebral cortex of mutant mice with CNS-restricted inactivation of ErbB4. Electroporation of human jM $\alpha$-ErbB4 into the brain of these mice, at E13.5, specifically rescued this phenotype.

In synthesis, Nrg1/ErbB4 seems to mainly act as a brake, filtering the astrogenic outcome of the cardinal Ct1/Jak2/Stat3 pathway and dictating the temporal frame of its emergence. In particular, strong Nrg1 signalling in early (<E14.5) murine cortico-cerebral precursors would prevent premature activation of astrogenesis, despite of early firing of the Ct1/Jak2/Stat3 axis. Then, subsequent dampening of Nrg1 signalling, due to late ErbB4 downregulation (Kornblum et al., 2000; Fox and Kornblum, 2005), would lead to progressive derepression of astrogenesis, eventually becoming the prevalent histogenetic process, at E18.5 and later.

\section{The pro-astrogenic Delta/Notch pathway}

It has been shown that artificial overactivation of Notch signalling in mouse E11.5 or rat E13 cortico-cerebral precursors leads - 2-3 weeks later - to increased astrocytic outputs. Consistently, an opposite phenotype occurs upon blockade of Notch signalling by the $\gamma$-secretase inhibitor N-[N-(3,5-Difluorophenacetyl)-L-alanyl]S-phenylglycine t-butyl ester (DAPT; Ge et al., 2002). As reported above, Notch signalling might sustain the astrogenic program thanks to the capability of Hes 1 and Hes5 to physically connect Jak2 to Stat3, so facilitating the phosphorylation of the latter and the transduction of the cardinal astrogenic signal (Kamakura et al., 2004). Additionally, Notch effectors Hes 1 and 5 might enhance astrogenesis by repressing transcription of proneural genes, endowed with antigliogenic properties (Kageyama et al., 2005). However, effectors of Notch signalling also directly interact with astroglial genes, so straightly regulating their transcription. One of these effectors is RBPJk, specifically binding to the Gfap promoter, circa $180 \mathrm{bps}$ upstream of the TSS. Another is the (unknown) interactor of another Notch-RE, mapped within the same promoter between -100bp and the TSS (Ge et al., 2002). Remarkably, although Notch signalling is already active within pre-neuronogenic cortico-cerebral 
precursors, astrogenesis initiates normally about 7 days later. This suggests that Notch signalling is not sufficient to trigger this process and addional conditions have to be fulfilled in order to unveil its pro-gliogenic power. Intriguingly, even artificial overstimulation of the Delta/Notch axis, while enhancing astrogenesis, does not anticipate it. Moreover, the astrogenic activity of Notch signalling requires Jak/Stat signalling, but not viceversa (Ge et al., 2002). Key of these phenomena might be the transcriptional corepressor NCoR and temporal regulation of its subcellular distribution pattern. In fact, this molecule is able to bind RBPJk (Kao et al., 1998) and is prevalently located within the nucleus of young neural precursors (Sardi et al., 2006). Therefore, specifically within these precursors, it might convert RBPJk into a trans-repressor, silencing astroglial genes. Then, when firing of the Jak2/Stat3 axis translocates NCoR to the cytoplasm (Sardi et al., 2006), RBPJk, freed from NCoR, would become prevalently complexed by Notch-IntraCytoplasmic-Domain (NICD) (Miller and Gauthier, 2007). As such, after E14.5, it might promote more and more transcription of astroglial genes. Consistently with this model, $70 \%$ of $\mathrm{NCoR}^{-/}$embryos show prominent cortico-cerebral overexpression of Gfap as early as E14.5, a time at which wild type cortices barely express this marker (Hermanson et al., 2002).

\section{The pro-astrogenic Tgf $\beta 1 /$ Tgf $\beta 1$ RI,II pathway}

It was originally reported that Tgf $\beta 1$ secreted by neurons and astrocytes induces the activation of the Gfap promoter in cultured astrocytes, so stimulating their maturation. In this respect, E14.5 neurons, expressing higher levels of $\operatorname{Tgf} \beta 1$, resulted to be more efficient inducers than E18.5 neurons and late embryonic astrocytes were more responsive to Tgf $\beta 1$ than late post-natal ones. Moreover, this Tgf $\beta 1$-dependent upregulation of Gfap was peculiar to cerebral cortex. Midbrain and cerebellar astroglia, while able to respond to Tgf $\beta 1$, did not display any increase of Gfap levels (De Sampaio e Spohr et al., 2002). More recently, it has been shown that Tgf $\beta 1$ signalling is not only implicated in late advancement of astrocyte differentiation, but may also help the commitment of pluripotent cortico-cerebral precursors to astroglial fates. In fact, the two Tgf $\beta 1$ receptors, Tgf $\beta R I$ and Tgf $\beta R I I$, and the Tgf $\beta 1$-signalling transducers, Smad2/3 and 4, are already expressed by the mouse E14.5 cortico-cerebral radial glia (RG). In this way, neuron-secreted Tgf $\beta 1$ may induce Smad2,3 translocation from RG cytoplasm to nucleus. This is followed by downregulation of the RG markers nestin and Blbp, and activation the astrocyte-lineage marker Gfap. (Stipursky and Gomes, 2007). However, two key aspects of progliogenic Tgf $\beta 1$ activity are still obscure. First, Tgf $\beta 1$ is abundantly expressed in intermitotic precursors and postmitotic neurons of the rat embryonic cortex as early as E16.5 (corresponding to mouse E14.5), and, at that time, astrogenesis is just going to be activated (Miller, 2003). Second, a Tgf $\beta 1$ response element has been detected within the Gfap promoter, at about 70 bases upstreatm the TSS, however binding of the intracellular Tgf $\beta 1$ effector pSmad2,3-BS to this element has not been yet demonstrated (Krohn et al., 1999). As for the first issue, the TF Foxg1, strongly expressed within telencephalic proliferative layers, has been proposed to interfere with multiple Tgf $\beta 1$ responses, by associating with DNA binding proteins which function as Smad2,3 partners (Dou et al., 2000). That could help to explain early hindering of the progliogenic Tgf $\beta 1$ activity. It might further suggest a possible mechanism for the reported Forkhead box g1 (Foxg1)-dependent inhibition of astrogenesis (Brancaccio et al.,
2010). As for the second issue, it is alternatively coinceivable that astrocytogenic results of $\operatorname{Tgf} \beta$ signalling do not require binding of pSmad2,3 to the Gfap promoter. It was shown that, upon activation by Tgf $\beta$, Tak1 interacts with Tab2 (Shibuya et al., 1996), namely a key component of the ErbB4-ICD/Tab2/NCoR complex, which mediates early Nrg1-dependent prevention of astrocytic transcriptions (Sardi et al., 2006). Therefore, Tgf $\beta 1$ might alternatively promote the astrogenic program, by sequestering - via the activated form of Tak1 - this essential cofactor of Nrg1 signalling (Stipursky and Gomes, 2007).

\section{The pro-astrogenic Pacap/Pac/Dream pathway}

A last trans-active pathway modulating cortico-cerebral astrogenesis is controlled by a ligand structurally related to Vasoactive Intestinal Peptide (Vip), termed Pituitary Adenylate CyclaseActivating Polypeptide (Pacap) (Vallejo, 2009). Cortical precursors express predominantly the short isoform of the Pacap-specific receptor Pac1, which couples to adenylate cyclase. Remarkably, even a short exposure of cortical precursors to Pacap results in a dose-dependent increase in cyclic adenylic acid (cAMP) production, which is strictly necessary to achieve Pacap-dependent promotion of astrogenesis (Vallejo and Vallejo, 2002). Moreover, Pacap raises intracellular calcium concentration via a mechanism that relies on extracellular calcium and requires cAMP. Eventually, calcium is the last intracellular transducer that triggers enhanced transcription of astroglial genes, in response to Pacap (Cebolla etal., 2008). Actually, it has been shown that, even in the absence of Pacap signalling, the transcriptional modulator Downstream Regulatory Element Antagonist Modulator (Dream) already sits near the Gfap-TSS, at two Dream-Responsive Elements, termed DRE1 and DRE2, located at $-381 /-359$ and $-70 /-51$, respectively. Then, the calcium wave triggered by Pacap induces Dream to undergo a profound conformational change, which makes it able to promote Gfap transcription. Cortical progenitors from Dream ${ }^{-/}$mice fail to express Gfap in response to Pacap, whereas Dream ${ }^{-/}$neural precursors, treated by Bdnf, generate about 2-fold more neurons. That suggests that the Pacap pathway contributes to the astrogenic-vs-neuronogenic histogenetic choice. Consistently, the neonatal cortex of $D^{2} \mathrm{am}^{-1}$ mice exhibits a reduced content of astrocytes. However this is a transient phenomenon, as Gfap ${ }^{+}$cells of these mutants, about $66 \%$ of controls at P1, bounce to $120 \%$ in as little as one week (Cebolla et al., 2008). Interestingly, the Pacap pathway seems to act independently of Jak2/Stat3. In fact, Dream knock-out does not affect the responsivity of cortico-cerebral precursors to Lif/Ctnf (Cebolla et al., 2008). Moreover, combined suboptimal stimulation of cortical precursors, by Pacap and $\mathrm{Cntf}$, elicits an additive incremental effect on frequency of Gfap+ cells (Cebolla and Vallejo, 2006). However, more subtle parameters of astroglial differentiation, such as the Gfap content of treated cultures and the morphological complexity of astrocytes, display a more than additive upregulation by Pacap and Cntf, so implying some cryptic functional interaction among the corresponding transduction pathways (Cebolla and Vallejo, 2006).

\section{Accessibility of chromatin to transcription}

It has been shown that, in addition to trans-active machineries impinging on astroglial promoters, proper activation and adequate progression of cortico-cerebral astrogenesis requires an appropriate temporal regulation of chromatin accessibility to transcription. 


\section{Large-scale changes of chromatin structure}

A first correlation has been described to occur between large scale chromatin configuration and the developmental choice taken by NSCs towards neuronal or astrocytic lineages. It turns out that the open configuration displayed by chromatin in young NSCs preferentially leads to self-renewal and neuronal differentiation, whereas its subsequent, progressive compaction biases stem cells to make astrocytes (Kishi et al., 2012). It is not clear how generalized changes of chromatin accessibility impact the histogenetic choice of NSCs. It is possible that such changes primarily reduce transcription rates of proneural genes and, because of the major trans-inhibitory role that proneural proteins exert on astrocyte-specific transcriptions (He et al., 2005), indirectly derepress astrogenesis. At least two gene sets have been implicated in modulating this epigenetic change.

High mobility group $\mathrm{A}(\mathrm{HmgA})$ proteins, 1 and 2, expressed at high level during early neuronogenesis, effectively compete with histone $\mathrm{H} 1$ for binding internucleosomal DNA linkers. In this way they keep chromatin accessible and promote the turnover of factors interacting with it, which is associated to prevalent neuronal differentiation. By the end of embryonic life, Hmga levels are reduced, which is possibly instrumental to upregulation of astrogenesis rates taking place at that time (Kishi et al., 2012). Consistently with this model, experimental manipulations of Hmga1/2 expression levels, both in vitro and in vivo, affect neurono-to-astrogenic ratios, indicating that these genes are both necessary and sufficient to orientate NSCs to neuronogenesis and inhibit gliogenesis (Kishi et al., 2012).

$N$-myc, expressed at high level during early neuronogenesis as well, conversely upregulates the histone acetyl-transferase gene GCN5. In this way, it promotes the acetylation of histones $\mathrm{H} 3$ and $\mathrm{H} 4$ as well as a more open chromatin configuration (Knoepfler et al., 2006). That may contribute to the capability of $N-m y c$ to sustain neuronogenesis. It may help $N$-myc to counteract expression and activity of $p 19($ Arf), which is strongly expressed in late NSCs and channel them to astroglial differentiation (Nagao et al., 2008).

\section{Epigenetic changes at proneural genes}

A neat trans-regulatory effect of the epigenetic state of neuronal genes on astrogenesis rates has been rigorously documented in the case of the proneural gene Ngn1. It has been found that the repressive mark trimethyl-histone 3 lysine 27 (H3K27me3) becomes more and more frequent near the Ngn1-TSS, in mouse E11.5 cerebral precursors kept in vitro for 3, 6 and 9 days. That is consistent with the progressive downregulation of Ngn1 occurring in vivo, around the end of the neuronogenic phase, and it is instrumental to late activation of astrogenesis (Hirabayashi et al., 2009). Actually, H3K27 trimethylation at the Ngn1-TSS depends on one of the two H3K27-methyltransferases included in the Polycomb Repressive Complex 2 (PRC2), enhancer of zeste homolog 2 (Ezh2). If Ezh2 is conditionally knocked-out at E13.5-14.5, then H3K27me3 levels at the Ngn1-TSS persist low and no downregulation of Ngn1 can be found around E17.5. Remarkably, this conditional knock-out is sufficient to shift the response of cortico-cerebral precursors to prodifferentiating agents in vitro, from from astrogenesis to neuronogenesis. In vivo, it dramatically reduces the frequency of $\mathrm{S} 100 \beta^{+}$cells, as evaluated in P1.5 cortices (Hirabayashi et al., 2009). Interestingly, a depression of astrogenesis may be also achieved by knocking down embryonic ectoderm development (Eed) (which encodes for another subunit of PRC2) or inactivating ring finger protein 1 gene (Ring1b) (which encodes for a subunit of the Polycomb Repressive Complex 1 (PRC1), a functional partner of PRC2) (Hirabayashi et al., 2009). Remarkably, the timing of these genomic manipulations is crucial to disclose the antigliogenic activity of PRC2, reasonably because of the involvement of this complex in additional decisional processes which precede the neurono-to-astrogenic switch. In fact, if Ezh2 is disrupted prior to neuronogenesis, then neuronogenesis rates are exaggerated, at expenses of precursors self-renewal, and the activation of astrogenesis is paradoxically anticipated (Pereira et al., 2010).

\section{Epigenetic changes at astroglial genes}

In addition to large scale chromatin dynamics and proper epigenetic tuning of proneural genes, it has been proven that a major pre-condition for the switch from neuronogenesis to astrogenesis is the progressive "opening" of astrocytic chromatin. This is a complex process which takes place while neuronogenesis is on, from E11.5 to E14.5 and beyond, and essentially consists in the acquisition by the astroglial genes of the capability to get bound by their specific transactivators (Hatada et al., 2008).

This capability depends first on the methylation state of DNA. Murine E11.5 cortico-cerebral precursors express the full set of molecular transducers of LiF-like signals (LiF-receptor subunits, Jaks and Stats among these). Exposed to LiF, they upregulate pStat3 to some extent. However, as it also happens in neurons and other non-neural cells, this does not result in Gfap transcription, because in these cells pStat3 cannot interact with its binding site, $1.5 \mathrm{~kb}$ upstream of the Gfap-TSS (Takizawa et al., 2001). In normal conditions, in fact, such interaction starts to be allowed only from $\mathrm{E} 14.5$, just upon natural $\mathrm{CpG}$ demethylation at this site. Remarkably, if DNA methylation is inhibited by 5 -azacytidine (5azaCdR) administration, then Gfap is activated already in E11.5 precursors, by only 4 days (Takizawa et al., 2001). An anticipation of astrogenesis also occurs upon knock-out of the "mainteinance" DNA methyl transferase gene, Dnmt1. In this case, E11.5 precursors, exposed to LIF, massively activate Gfap and $S 100 \beta$ in as little as 2 days in vitro, whereas their wild type counterpart would take 7 more days for that (Fan et al., 2005). More recently, demethylation of astroglial genes just prior to glial differentiation of NSCs has been described in a variety of other cases (AldoC, ATP-sensitive inward rectifier potassium channel 10 gene (Kcnj10), serpin peptidase inhibitor b8 gene (Serpinb8) and SRY-box containing gene 8 (Sox8) among them). Nowadays it is considered as a pervasive phenomenon, crucial to timely activation of the astrogenic program (Hatada et al., 2008).

However, the preparation of astrocytic genes to transcription is

TABLE 1

\section{MAIN EFFECTORS MODULATING THE EPIGENETIC STATE OF THE GFap PROMOTER}

\begin{tabular}{lll} 
Effector & Effects on the Gfap promoter & References \\
\hline Nf1a & $5 \mathrm{meC} \downarrow$ & (Namihira et al., 2009) \\
Fgf2 $^{\star}$ & $5 \mathrm{meC} \downarrow, \mathrm{H} 3 \mathrm{~K} 9-\mathrm{me} 2 \downarrow, \mathrm{H} 3 \mathrm{~K} 4-\mathrm{me} 2 \uparrow$ & (Song and Ghosh, 2004) \\
Coup-tf1,2 & $5 \mathrm{meC} \downarrow, \mathrm{H} 3 \mathrm{~K} 9-\mathrm{me} 2 \downarrow, \mathrm{H} 3 \mathrm{~K} 4-\mathrm{me} 2 \uparrow, \mathrm{H} 3-\mathrm{ac} \uparrow$ & (Naka et al., 2008) \\
RA & $\mathrm{H} 3-\mathrm{ac} \uparrow$ & (Asano et al., 2009) \\
Eset & H3K9-me3 $\uparrow, \mathrm{H} 3 \mathrm{~K} 9$-ac $\downarrow$ & (Tan et al., 2012) \\
Brg1 & chrom remodeling & (Matsumoto et al., 2006) \\
\hline
\end{tabular}

* requires subsequent Ctnf stimulation to be effective 
not limited to proper regulation of their DNA methylation levels. It encompasses also a fine modulation of the covalent modification profile of histones associated to them, as well a conformational rearrangement of chromatin (Matsumoto et al., 2006). The former includes the replacement of the dimethyl-histone 3 lysine 9 mark (H3K9me2) by the dimethyl-histone 3 lysine 4 mark (H3K4me2), a phenomenon originally documented at the pStat3-BS of Gfap, within ratE15.5 cortico-cerebral precursors kept 2 days in vitrounder Fgf2. Remarkably, this switch is associated to $\mathrm{H} 3$ hyperacetylation and was proven to be sufficient and necessary to make Gfap suitable to transcription (Song and Ghosh, 2004).

Complex molecular mechanisms dictate the epigenetic state of astroglial chromatin. At the moment, at least six main players have been shown to master this control: Notch (via Nuclear Factor la, NFla), Fgf2, Couptf1\&2, retinoic acid, RA (via RA-Receptors $\alpha$, $\beta$ and $X, R A R \alpha, R A R(\beta$ and $R X R)$, the histone 3 lysine 9-methyltransferase (H3K9-MT) ERG-associated protein with SET domain (ESET) and one of the two ATPase subunits of the SWItch/Sucrose NonFermentable (SWI/SNF) chromatin remodeling complex, namely the product of Brahma related gene 1, Brg1 (see Table 1 and Fig. 4).

It was early recognized that Notch signalling modulate corticocerebral histogenesis in a stepwise way, initially inhibiting neuronogenesis and subsequently promoting astrogenesis at expenses of oligogenesis (Grandbarbe et al., 2003). Actually, the Notch receptor is expressed by apical precursors since E10.5-11.5. Its Delta-like ligands are early detectable on the plasma membrane of the same cells according to an early, dynamical salt-and-pepper blueprint (Shimojo et al., 2008). Then, they are expressed, more and more, by basal precursors and newborn neurons (Yoon et al., 2008). It was shown that artificial hyperstimulation of Notch signalling in E11.5 cortico-cerebral precursors makes these cells able to activate Gfap within 3 days in vitro, in response to Lif stimulation. Blockade of Notch signalling conversely suppresses this ability and inhibits astrogenesis in vivo. As for the underlying molecular mechanism, it was shown that canonical Notch signalling is sufficient and necessary to promote demethylation of the main pStat3-BS located in the Gfap promoter. That normally happens between E11.5 and E14.5 and it is a pre-condition for subsequent activation of this gene by Lif-like ligands (Namihira et al., 2009). Gfap demethylation is associated to reduced binding of the "maintenance" Dnmt1 enzyme to the Gfap promoter, induced by Notch signalling, and requires precursors proliferation (possibly allowing the dilution of the previously established 5-methylcytosine (5meC) marks). However, notice that the Delta/Notch axis does not repress Dnmt1 expression, conversely, it simply forces Dnmt1 to detach from the Gfap promoter. Actually, the Notch effector RBPJk binds to the Nf1a promoter, about $2.0 \mathrm{~kb}$ upstream of its TSS, and stimulates its transcription (Namihira et al., 2009). In turn, Nf1a binds to the Gfap promoter (at least four Nf1a binding sites were found within the Gfap promoter (Cebolla and Vallejo, 2006; Piper et al., 2010)). This is necessary and sufficient to detach Dnmt1 from this region and get it demethylated, so paving the way to the astrogenic program (Namihira et al., 2009). That was assessed, by overexpressing Nf1a (or a dominant negative version of it) in E11.5 cortico-cerebral precursors, and assaying their behaviour in vitro, after 4 days of Lif stimulation. Thus, Nf1a mediates the pro-astrogenic function of the Delta/Notch axis, being transcribed in response to Notch signalling and possibly competing with Dnmt1 for binding to the Gfap promoter (Namihira et al., 2009). Remarkably, overstimulation of the Delta/Notch/Nfla axis is not sufficient per se to enhance astrogenesis. The pro-astrogenic activity of this pathway only emerges, provided that the system is co-stimulated
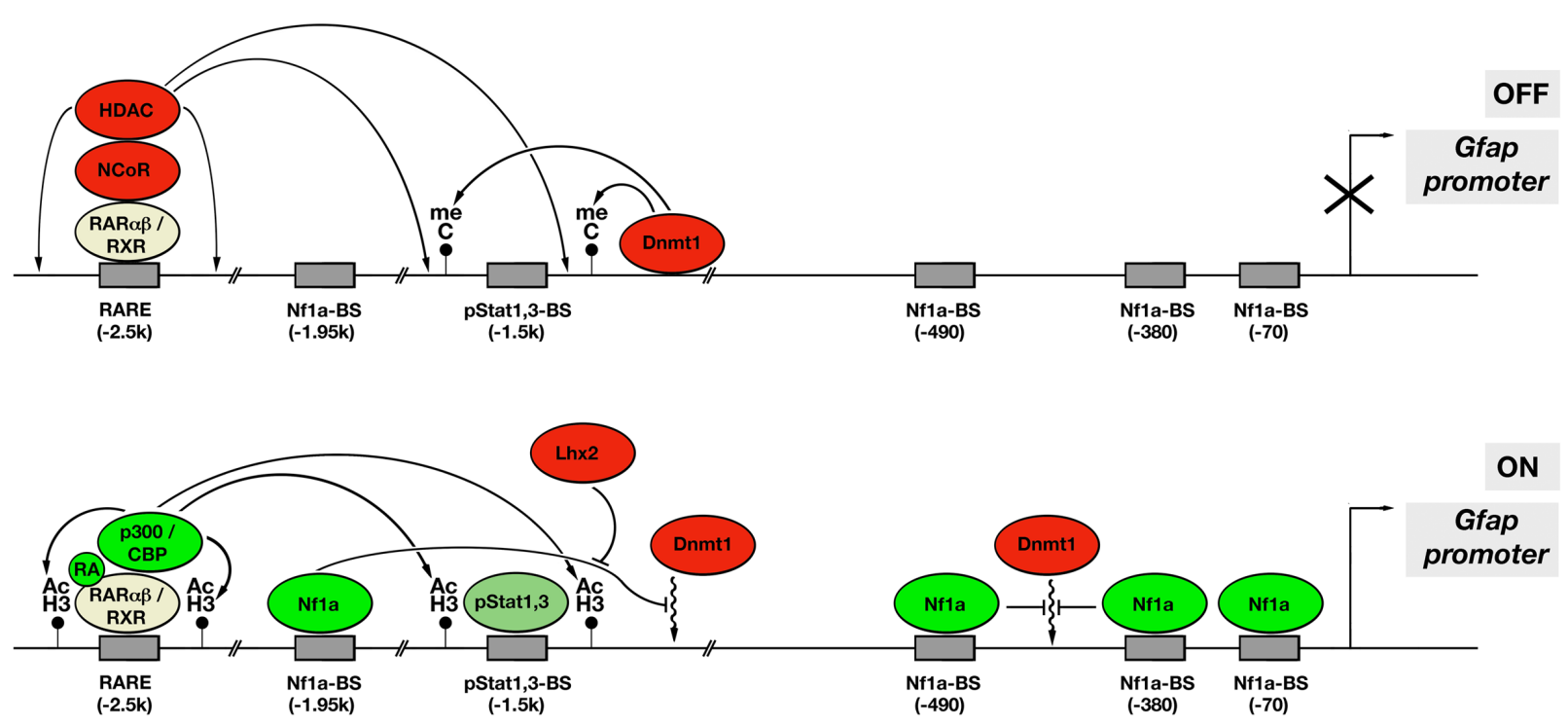

Fig. 4. Epigenetic regulation of the Gfap promoter by Nf1a and RA. (OFF state). In the absence of Nf1a, Dnmt1 C5-methylates the surroundings of the pStat1,3-binding site, at -1.5kb, making such site not suitable to interact with its cognate transactivator. Meanwhile, in the absence of RA, the $R A R \alpha, \beta / R X R$ receptor sits on the RARE at $-2.5 \mathrm{~kb}$ and, via an NCoR bridge, recruits histone deacetylases (HDACs). These ones deacetylate the Gfap promoter, around both $-2.5 \mathrm{~kb}$ and $-1.5 \mathrm{~kb}$, so contributing to shut down transcription. (ON state). Nf1a binds to the Gfap promoter, possibly at as many as four distinct locations, and inhibits Dnmt1 interaction with it, so allowing progressive lose of C5-methyl marks. Limited to the archicortex, Lhx2 counteracts this Nf1a-dependent inhibition of Dnmt1, so antagonizing astrogenesis arousal. On the other side, RA changes the conformational state of its RARE-bound RAR $\alpha, \beta / R X R$ receptor, leading to replacement of NCoR-HDAC by $p 300 / C B P$. As a consequence of that, the Gfap promoter is richly acetylated and so made prone to transcription. 
by Lif (Namihira et al., 2009) and/or Pacap (Cebolla and Vallejo, 2006). Consistently, if the NF1a-binding site -79/-57 bps upstream the Gfap-TSS is dirsrupted, then the responsivity of the Gfap promoter to both Ctnf and Pacap is suppressed and even basal transcription of this gene collapses (Cebolla and Vallejo, 2006). It is worth mentioning that this mechanism seems to be not limited to Gfap. In fact, Nf1a-BSs can be found in the promoters of other astroglial genes (including $S 100 \beta$, aquaporin4, and clusterin), Nf1a binds to these sites upon activation of the Notch pathway, and $\mathrm{Nf1a}$ overexpression is sufficient to induce demethylation of the corresponding promoters (Namihira et al., 2009). More recently, it has been shown that electroporation of the LIM homeobox 2 TF gene $L h x 2$ into the E15/17 ventricular zone reduces astrogenesis rates by almost $2 / 3$-fold and prevents exaggerated astrogenesis induced by Nf1a overexpression. On the other side, disruption of Lhx2 activity, by E15.5 electroporation of its dominant-negative cofactor gene Clim $\triangle D D$, magnifies astrogenesis at expenses of neuronogenesis, only provided that $N f 1 a$ is not ablated. In a few words, Lhx2 seems to inhibit transcription of astroglial genes, by preventing the activity of Nf1a on their promoters (Subramanian et al., 2011). However, these phenomena were documented exclusively in the archicortical anlage, where the late gestational drop of $L h x 2$ expression levels may contribute to perinatal upregulation of astrogenesis. No gliogenic anomaly was conversely found upon manipulation of Lhx2 activity in neocortical precursors (Subramanian et al., 2011). Finally, in addition to promoting primary opening of Gfap chromatin, Nf1a might further sustain transcription of this chromatin at more advanced steps of astroglial differentiation, synergizing with its later activated paralogs, Nf1b, Nf1c and Nf1x (Wilczynska et al., 2009).

As for Fgf2, it was reported that the exposure of E18 rat corticocerebral precursors to this GF for as little as 6 hours makes them responsive to a subsequent 24 hours $C$ ntf stimulation. This results into a remarkable upregulation of Gfap, which, conversely, does not respond to the Cntf treatment alone. Consistently, these precursors, exposed to combined Fgf 2 and Cntf for 6 days, give rise to 3-fold less neuronal clones and 2-fold more astrocytic clones. Concerning mechanisms of action of Fgf2, this factor does not influence expression or phosphorylation of Stat3. As proven by ChIP, it conversely triggers the replacement of H3K9me2 with H3K4me2 at the pStat3-BS of the Gfap promoter. However how does it happen, it is not known (Song and Ghosh, 2004). Moreover, Fgf2, stimulating proliferation, contributes to the "dilution" of the 5methylcitosines originally clustered at the Gfap and $5100 \beta$ promoters, which occurs upon the Notch-induced detachment of Dnmt1 from these promoters (Namihira et al., 2009). In these ways, Fgf2 allows pStat3 to bind to the astrocytic promoters and stimulate transcription (Song and Ghosh, 2004; Namihira et al., 2009).

Among agents promoting the opening of astrocyte genes chromatin, there are also the two TF genes Coup-tf1 and 2. Coup-tfs are widely expressed in the telencephalic ventricular zone, where they display a transient peak around E12.5. Their involvement in astrogenesis was recognized by an elegant shRNA screening, run in embryoid body- (EB)-derived neurospheres. It was found that shRNA-mediated silencing of Coup-tfs juvenilizes these cultures, increasing the neuronal output obtainable from tertiary neurospheres under Lif/Bmp stimulation, and reducing the astrocytic one. Consistently, lentivirus-mediated repression of Coup-tfs in cortico-cerebral precursors, from E12.5 onward, resulted - at P20
- in doubling of their neuronal progenies as well as in a dramatic shrinkage of their astrocytic output. Moreover, when Coup-tfs knock-down was anticipated to E10.5, then the switch from deep layer- to superficial layer-neurons production was defective too. This suggests that beyond astrogenesis activation, these two factors may play a more general role as promoters of pan-histogenetic progression. Interestingly, however, neither Coup-tf1 not Coup-tf2 are sufficient to anticipate the onset of astrogenesis, so pointing toward a permissive rather than instructive role. Remarkably, the two Coup-tfs exert only a moderate influence on the expression levels of key trans-active factors modulating astrogenesis. Their impact on gliogenesis is probably mediated by the epigenetic changes they evoke on the chromatin of astrocytic genes. That has been shown at the level of the pStat3-BS the Gfap promoter. Here, their knock-down upregulates H3K9me2 levels, at expenses of $\mathrm{H} 3 \mathrm{~K} 4 \mathrm{me} 2$ and acetylated-histone 3 (H3ac), and leads to increased $\mathrm{CpG}$ methylation. However these effects are not direct. In fact, no straight interaction of Coup-tfs with the Gfap promoter was detected and both Coup-tfs were shown to play their pro-gliogenic role as transcriptional repressors (Naka et al., 2008).

Retinoic acid (RA), administered to murine E14.5 telencephalic precursors, synergizes with Lif in inducing the activation of the Gfap gene (within as little as 2 days). In the absence of RA, the RAR $\alpha \beta / R X R$ complex sits on a retinoic acid responsive element (RARE) located at circa $2.5 \mathrm{~kb}$ upstream of the Gfap transcriptional start site, possibly recruiting specific corepressors (NCoR and/ or silencing mediator for retinoid or thyroid-hormone receptors (SMRT)) to the chromatin. This makes chromatin hypoacetylated, both near the RARE and around the major STAT3 BS, at $-1.5 \mathrm{~kb}$, and inhibits transcription. Upon binding of RAto RAR $\alpha$, the RAR $\alpha \beta /$ $\mathrm{RXR}$ complex releases the corepressor(s) and recruits the histone acetyl transferase (HAT) E1A binding protein p300/CRB binding protein (p300/CBP), so increasing histone acetylation at both $-2.5 \mathrm{~kb}$ and $-1.5 \mathrm{~kb}$. This makes the pStat3-BS suitable to be bound by pStat3 and leads to LIF-dependent transcriptional activation (Asano et al., 2009).

ESET mRNA, encoding for the histone methyl transferase $\mathrm{KMT1E}$, is expressed by the neuronogenic cortico-cerebral ventricular zone at progressively decreasing levels, almost disappearing prior to birth. Its experimental inactivation derepresses transcription of non-neural genes and endogenous retroviral (ERV) sequences and distorts temporal articulation of the cortical histogenetic schedule. ESET ablation anticipates both upper layer neurons generation and astrogenesis onset. Moreover, it hastens the subsequent increase of astrogenic rates. Conversely, in utero electroporation of ESET antagonizes astrogenesis, although not fully suppressing it. KMT1E binds to the Gfap promoter, it is necessary for its H3K9 trimethylation and prevents its $\mathrm{H} 3 \mathrm{~K} 9$ acetylation. As such, it contributes to the complex machinery which controls timed opening of astroglial genes chromatin and allows timely activation of astroglial programs (Tan et al., 2012). Based on the detection of a number of Hes1-binding sites in its promoter, it has been suggested that the ESET transcription unit might "sense" cell-cycle-locked Hes1 pulsation, integrate digital information encapsulated within such pulsation and convert such information into a cell-cycle numberdependent analog output, in charge of modulating the rates of the histogenic processes (Tan et al., 2012).

Finally, it is worth mentioning that a supportive role for astrogenesis is played by Brg1, encoding for one of the two catalytic 
ATPase subunits of the SWI/SNF chromatin remodeling complex (Matsumoto et al., 2006). Brg1 is expressed by cortical neurons and is activated in the cortical ventricular zone after E13.5. Its early ablation impairs self-renewal of neural precursors and results into a depleted astrogenic pool, as proven by the dramatic downregulation of CD44, S100 $\beta$ and Gfap. Interestingly, if Brg1 ablation is postponed (by infecting E14.5 Brg $1^{\mathrm{fl} / \mathrm{fl}}$ cortico-cerebral precursors with adenoviral cre-expressors, in vitro), then the proliferating pool is spared, however its astroglial differentiation is still very poor, suggesting a specific involvement of this gene in activation of the astrogenic program. Molecular details of this involvement are presently unknown (Matsumoto et al., 2006).

\section{Regulation of astrocyte committed progenitor prolif- eration}

Our knowledge of such regulation is still very poor and only a few genes have been implicated in it. Fgf2 and Egf stimulate proliferation of neonatal rodent astroblasts (Mayer et al., 2009; Riboni et al., 2001). Fibroblast growth factor 9 (Fgf9) promotes a substantial expansion of the perinatal astrogenic proliferating pool (Seuntjens etal., 2009) and delays terminal differentiation of mature astrocytes (Lum et al., 2009). Smad interacting protein 1 (Sip1) TF limits astroblasts proliferation, possibly by inhibiting Fgf9 expression (Seuntjens et al., 2009). A reduction of late astrocyte progenitors, compared to early, NSC-born ones, occurs upon overexpression of the TFs Foxg1 and Empty spiracle homolog 2 (Emx2) in NSCs, suggesting that astrocyte progenitors might undergo precocious terminal differentiation (Brancaccio et al., 2010).

Finally, it has been shown that cortical ablation of the TF Olig2 leads to a dramatic upregulation of Gfap in the neocortical postnatal grey matter, pointing to a possible prolonged persistence of astrocytes in a proliferating state. However, kinetic analysis of Olig2-LOF mutants ruled out this hypothesis, suggesting that this phenotype might rather reflect defective Gfap silencing in $\mathrm{S} 100 \beta^{+}$ cells of grey matter (Cai et al., 2007). Conversely Olig2, upregulated in reactive adult astrocytes, is strictly necessary to sustain their proliferation and the formation of the glial scar (Chen et al., 2008).

\section{Concluding remarks}

In synthesis, several interlaced molecular machineries regulate proper progression of cortico-cerebral astrogenesis.

Astrogenesis timing is firstly determined by temporally regulated accessibility of astrocytic promoters to transactive complexes stimulating their transcription. Undoubtedly, this is the main factor preventing precocious astrocyte generation within the early neuronogenic pallium. Distinct machineries, acting on both DNA and histones, contribute to such regulation. Three factors promote DNA demethylation at astrocytic promoters: the RBPJk target Nf1a removes the methylating Dnmt1 enzyme from these promoters; Fgf2 likely dilutes previously acquired C5-methyl marks; Couptf1,2 act according to still unknown mechanisms. As for histones, three factors promote a transcription-prone profile: Fgf2 and Couptf1,2 induce the replacement of $\mathrm{H} 3 \mathrm{~K} 9-\mathrm{me} 2$ by H3K4-me2; RA, secreted by telencephalic menginges, evokes $\mathrm{H} 3$ hyperacetylation. Conversely, progressive downregulation of the H3K9 trimethylating enzyme ESET possibly contributes to sharp astrogenesis activation in neural precursors which have completed neuronogenesis.

Moreover, temporal tuning of astrogenic rates is further refined by regulated firing of a specific transactive pathways impinging on astroglial promoters.

Astrocyte-specific transcriptions are mainly promoted by $\mathrm{Ct} 1$ family cytokines, via the intracellular Jak/Stat transducing axis. In this respect, both ligands availability and neural precursors responsivity to them are crucial to proper temporal progression of astrogenesis. Astrocyte-specific transcriptions are triggered by neuron-secreted $\mathrm{Ct} 1$, accumulating by the end of neuronogenesis, and they are later potentiated by Cntf, released by newborn astrocytes. Besides, sensitivity of neural precursor to these cytokines, very low around the onset of neuronogenesis, gets higher and higher, as neuronogenesis proceeds. This is due to progressive autoactivation of the Jak/Stat transduction axis, via pStat3-dependent transcription of gp130, Jak1, Stat1 and Stat3, as well as to the effects of additional regulatory branches feeding this axis. These are: Mek/Erk and Egf/ Tgf $\alpha$ signalling (arising during prenatal life), which upregulate gp130 and Stat3, respectively; Hes1,5 (expressed by apical precursors in response to neuronal-progenitor Delta signalling), which ease pJak2-dependent Stat3 phosphorylation; and p19 (arising in the late pallium upon decrease of it early repressor $\mathrm{N}$-myc), which also facilitates pJak2-dependent Stat3 phosphorylation.

On the other side, two additional transactive agents, expressed at higher level during early neuronogenesis and fading out around its completion, Neurogenins (Ngns) and ErbB4, antagonize astrogenesis, preventing its large scale activation around mid-neuronogenesis. Ngns inhibit transcription of four key effectors of the Ct1 transduction axis (gp130, Jak1, Stat1 and Stat3), counteract pJak2-dependent Stat3 phosphorylation and further compete with pStat 1,3 for limited amounts of the p300/CBP-pSmad2,4 complex, available upon Bmp signalling. The intracytoplasmic domain (ICD) of ErbB4, detaching from cell plasma membrane upon Nrg1 stimulation, promotes the translocation of the transcriptional corepressor NCoR into the nucleus, where it contributes to inhibit Gfap transcription, being likely conveyed to its promoter by an RBPJk bridge.

Finally, relatively little is known about mechanisms which, once macroglial differentiation has been initiated, modulate proliferation and differentiation rates of astrocyte-committed progenitors, so dictating the final astroglial output of the system. A few transcription factors (Sip1, Emx2 and Foxg1) as well a few secreted ligands (Fgf9 and Tgf $\alpha$ ) have been implicated in this issue. However, molecular details of their action as well as their reciprocal epistatic relationships were poorly clarified. They will be likely subjects of future investigations.

\section{References}

ABBOTTNJ, RÖNNBÄCKL, ANDHANSSONE (2006). Astrocyte-endothelial interactions at the blood-brain barrier. Nature Rev Neurosci 7: 41-53.

ABERG MA, RYTTSÉN F, HELLGREN G, LINDELL K, ROSENGREN LE, MACLENNAN AJ, CARLSSON B, ORWAR O, AND ERIKSSON PS (2001). Selective introduction of antisense oligonucleotides into single adult CNS progenitor cells using electroporation demonstrates the requirement of STAT3 activation for CNTF-induced gliogenesis. Mol Cell Neurosci 17: 426-443.

ADACHI T, TAKANAGA H, KUNIMOTO M, AND ASOU H (2005). Influence of LIF and BMP-2 on differentiation and development of glial cells in primary cultures of embryonic rat cerebral hemisphere. J Neurosci Res 79: 608-615.

ALLEN NJ, AND BARRES BA (2009). Neuroscience: Glia - more than just brain glue. Nature 457: 675-677.

ALVAREZ JI, DODELET-DEVILLERS A, KEBIR H, IFERGAN I, FABRE PJ, TEROUZ S, SABBAGH M, WOSIK K, BOURBONNIĖRE L, BERNARD M, et al. (2011). The Hedgehog pathway promotes blood-brain barrier integrity and CNS immune 
quiescence. Science 334: 1727-1731.

ASANOH, AONUMAM, SANOSAKAT, KOHYAMAJ, NAMIHIRAM, AND NAKASHIMA $\mathrm{K}$ (2009). Astrocyte differentiation of neural precursor cells is enhanced by retinoic acid through a change in epigenetic modification. Stem Cells 27: 2744-2752.

ASSIMACOPOULOS S, GROVE EA, AND RAGSDALE CW (2003). Identification of a Pax6-dependent epidermal growth factor family signaling source at the lateral edge of the embryonic cerebral cortex. J Neurosci 23: 6399-6403.

AZEVEDO FAC, CARVALHO LRB, GRINBERG LT, FARFEL JM, FERRETTI REL, LEITE REP, FILHO WJ, LENT R, AND HERCULANO-HOUZEL S (2009). Equal numbers of neuronal and nonneuronal cells make the human brain an isometrically scaled-up primate brain. J Comp Neurol 513: 532-541.

BACHOO RM, KIM RS, LIGON KL, MAHEREA, BRENNANC, BILLINGS N, CHANS, LIC, ROWITCHDH, WONG WH, etal. (2004). Molecular diversity of astrocytes with implications for neurological disorders. Proc Natl Acad Sci USA 101: 8384-8389.

BALLAS N, LIOY DT, GRUNSEICH C, AND MANDEL G (2009). Non-cell autonomous influence of MeCP2-deficient glia on neuronal dendritic morphology. Nature Neurosci 12: 311-317.

BANDEIRA F, LENT R, AND HERCULANO-HOUZELS (2009). Changing numbers of neuronal and non-neuronal cells underlie postnatal brain growth in the rat. Proc. Natl. Acad. Sci. USA 106: 14108-14113.

BARNABÉ-HEIDER F, WASYLNKA JA, FERNANDES KJL, PORSCHE C, SENDTNER M, KAPLAN DR, AND MILLER FD (2005). Evidence that embryonic neurons regulate the onset of cortical gliogenesis via cardiotrophin-1. Neuron 48: 253-265.

BÉLANGER M, ALLAMAN I, AND MAGISTRETTI PJ (2011). Brain energy metabolism: focus on astrocyte-neuron metabolic cooperation. Cell Metab 14: 724-738.

BLADER P (2004). Conserved and acquired features of neurogenin1 regulation. Development 131: 5627-5637.

BLOBEL CP (2005). ADAMs: key components in EGFR signalling and development. Nature Rev Mol Cell Biol 6: 32-43.

BONNI A, SUN Y, NADAL-VICENS M, BHATT A, FRANK DA, ROZOVSKY I, STAHL N, YANCOPOULOS GD, AND GREENBERG ME (1997). Regulation of gliogenesis in the central nervous system by the JAK-STAT signaling pathway. Science 278: 477-483.

BOZOYAN L, KHLGHATYAN J, AND SAGHATELYAN A (2012). Astrocytes control the development of the migration-promoting vasculature scaffold in the postnatal brain via VEGF signaling. J Neurosci 32: 1687-1704.

BRANCACCIO M, PIVETTA C, GRANZOTTO M, FILIPPIS C, AND MALLAMACI A (2010). Emx2 and Foxg1 inhibit gliogenesis and promote neuronogenesis. Stem Cells 28: 1206-1218.

BURROWS RC, WANCIO D, LEVITT P, AND LILLIEN L (1997). Response diversity and the timing of progenitor cell maturation are regulated by developmental changes in EGFR expression in the cortex. Neuron 19: 251-267.

CAHOY JD, EMERY B, KAUSHALA, FOO LC, ZAMANIAN JL, CHRISTOPHERSON KS, XING Y, LUBISCHER JL, KRIEG PA, KRUPENKO SA, et al. (2008). A transcriptome database for astrocytes, neurons, and oligodendrocytes: a new resource for understanding brain development and function. J Neurosci 28: 264-278.

CAI J, CHEN Y, CAI W-H, HURLOCK EC, WU H, KERNIE SG, PARADA LF, AND LU QR (2007). A crucial role for Olig2 in white matter astrocyte development. Development 134: 1887-1899.

CAO F, HATA R, ZHU P, MA Y-J, TANAKA J, HANAKAWA Y, HASHIMOTO $K$, NIINOBE M, YOSHIKAWA K, AND SAKANAKA M (2006). Overexpression of SOCS3 inhibits astrogliogenesis and promotes maintenance of neural stem cells. J Neurochem 98: 459-470.

CAO F, HATA R, ZHU P, NAKASHIRO K, AND SAKANAKA M (2010). Conditional deletion of Stat3 promotes neurogenesis and inhibits astrogliogenesis in neural stem cells. Biochem Biophys Res Commun 394: 843-847.

CARIC D, RAPHAEL H, VITI J, FEATHERS A, WANCIO D, AND LILLIEN L (2001). EGFRs mediate chemotactic migration in the developing telencephalon. Development 128: 4203-4216.

CEBOLLA B, AND VALLEJO M (2006). Nuclear factor-I regulates glial fibrillary acidic protein gene expression in astrocytes differentiated from cortical precursor cells. $J$ Neurochem 97: 1057-1070.

CEBOLLA B, FERNÁNDEZ-PÉREZ A, PEREA G, ARAQUE A, AND VALLEJO M (2008). DREAM mediates cAMP-dependent, Ca2+-induced stimulation of GFAP gene expression and regulates cortical astrogliogenesis. JNeurosci28:6703-6713.
CHEN Y, MILES DK, HOANG T, SHI J, HURLOCK E, KERNIE SG, AND LU QR (2008). The Basic Helix-Loop-Helix Transcription Factor Olig2 Is Critical for Reactive Astrocyte Proliferation after Cortical Injury. J Neurosci 28: 10983-10989.

DASGUPTAB, AND GUTMANN DH (2005). Neurofibromin regulates neural stem cell proliferation, survival, and astroglial differentiation in vitro and in vivo. J Neurosci 25: 5584-5594.

DEROUET D, ROUSSEAU F, ALFONSI F, FROGER J, HERMANN J, BARBIER F, PERRET D, DIVEU C, GUILLET C, PREISSER L, et al. (2004). Neuropoietin, a new IL-6-related cytokine signaling through the ciliary neurotrophic factor receptor. Proc. Natl. Acad. Sci. USA 101: 4827-4832.

DIEZ-ROUX G, BANFI S, SULTAN M, GEFFERS L, ANAND S, ROZADO D, MAGEN A, CANIDIO E, PAGANI M, PELUSO I, et al. (2011). A high-resolution anatomical atlas of the transcriptome in the mouse embryo. PLOS Biol 9: e1000582.

DOREYK, AND AMAYAE (2010). FGF signalling: diverse roles during early vertebrate embryogenesis. Development 137: 3731-3742.

DOU C, LEE J, LIU B, LIU F, MASSAGUE J, XUAN S, AND LAI E (2000). BF-1 interferes with transforming growth factor beta signaling by associating with Smad partners. Mol Cell Biol 20: 6201-6211.

ERNST M, AND JENKINS BJ (2004). Acquiring signalling specificity from the cytokine receptor gp130. Trends Genet 20: 23-32.

EROGLU C, AND BARRES BA (2010). Regulation of synaptic connectivity by glia. Nature 468: 223-231.

FAN G, MARTINOWICH K, CHIN MH, HE F, FOUSE SD, HUTNICK L, HATTORI $\mathrm{D}, \mathrm{GE} \mathrm{W}, \mathrm{SHEN} \mathrm{Y,WU} \mathrm{H}$, et al. (2005). DNA methylation controls the timing of astrogliogenesis through regulation of JAK-STAT signaling. Development 132 : 3345-3356.

FOX IJ, AND KORNBLUM HI (2005). Developmental profile of ErbB receptors in murine central nervous system: implications for functional interactions. J Neurosci Res 79: 584-597.

FUKUDA S, KONDO T, TAKEBAYASHI H, AND TAGA T (2004). Negative regulatory effect of an oligodendrocytic bHLH factor OLIG2 on the astrocytic differentiation pathway. Cell Death Differ 11: 196-202.

GADIENT RA, LEIN P, HIGGINS D, AND PATTERSON PH (1998). Effect of leukemia inhibitory factor (LIF) on the morphology and survival of cultured hippocampal neurons and glial cells. Brain Res 798: 140-146.

GAUTHIER AS, FURSTOSS O, ARAKI T, CHAN R, NEEL BG, KAPLAN DR, AND MILLER FD (2007). Control of CNS cell-fate decisions by SHP-2 and its dysregulation in Noonan syndrome. Neuron 54: 245-262.

GE W, MARTINOWICH K, WU X, HE F, MIYAMOTO A, FAN G, WEINMASTER G, AND SUN YE (2002). Notch signaling promotes astrogliogenesis via direct CSLmediated glial gene activation. J Neurosci Res 69: 848-860.

GE W-P, MIYAWAKI A, GAGE FH, JAN YN, AND JAN LY (2012). Local generation of glia is a major astrocyte source in postnatal cortex. Nature 484: 376-380.

GORSKI JA, TALLEY T, QIU M, PUELLES L, RUBENSTEIN JLR, AND JONES KR (2002). Cortical excitatory neurons and glia, but not GABAergic neurons, are produced in the Emx1-expressing lineage. J Neurosci 22: 6309-6314.

GRANDBARBE L, BOUISSAC J, RAND M, HRABÉ DE ANGELIS M, ARTAVANISTSAKONASS, AND MOHIERE (2003). Delta-Notch signaling controls the generation of neurons/glia from neural stem cells in a stepwise process. Development 130: 1391-1402.

GROVE EA, WILLIAMS BP, LI DQ, HAJIHOSSEINI M, FRIEDRICH A, AND PRICE $J$ (1993). Multiple restricted lineages in the embryonic rat cerebral cortex. Development 117: 553-561.

GU F, HATA R, MA Y-J, TANAKA J, MITSUDA N, KUMON Y, HANAKAWA Y, HASHIMOTO K, NAKAJIMA K, AND SAKANAKA M (2005). Suppression of Stat3 promotes neurogenesis in cultured neural stem cells. J Neurosci Res 81: 163-171.

GUILLEMOT F (2005). Cellular and molecular control of neurogenesis in the mammalian telencephalon. Curr Opin Cell Biol 17: 639-647.

HAN SSW, LIUY, TYLER-POLSZC, RAOMS, AND FISCHERI (2004). Transplantation of glial-restricted precursor cells into the adult spinal cord: survival, glial-specific differentiation, and preferential migration in white matter. Glia 45: 1-16.

HATADA I, NAMIHIRA M, MORITA S, KIMURA M, HORII T, AND NAKASHIMA K (2008). Astrocyte-specific genes are generally demethylated in neural precursor cells prior to astrocytic differentiation. PLOS ONE 3: e3189.

HE F, GE W, MARTINOWICH K, BECKER-CATANIA S, COSKUN V, ZHU W, WU H, 
CASTRO D, GUILLEMOT F, FAN G, et al. (2005). A positive autoregulatory loop of Jak-STAT signaling controls the onset of astrogliogenesis. Nature Neurosci 8: 616-625

HEGEDUS B, DASGUPTA B, SHIN JE, EMNETT RJ, HART-MAHON EK, ELGHAZI L, BERNAL-MIZRACHI E, AND GUTMANN DH (2007). Neurofibromatosis-1 regulates neuronal and glial cell differentiation from neuroglial progenitors in vivo by both cAMP- and Ras-dependent mechanisms. Cell Stem Cell 1: 443-457.

HERCULANO-HOUZEL S (2012). The remarkable, yet not extraordinary, human brain as a scaled-up primate brain and its associated cost. Proc. Natl. Acad. Sci. USA 109: 10661-10668.

HERCULANO-HOUZELS, RIBEIRO P, CAMPOS L, VALOTTADASILVAA, TORRES LB, CATANIA KC, AND KAAS JH (2011). Updated Neuronal Scaling Rules for the Brains of Glires (Rodents/Lagomorphs). Brain, Behavior and Evolution 78:302-314.

HERMANSON O, JEPSEN K, AND ROSENFELD MG (2002). N-CoR controls differentiation of neural stem cells into astrocytes. Nature 419: 934-939.

HILGETAG CC, AND BARBAS H (2009). Are there ten times more glia than neurons in the brain? Brain Struct Funct 213: 365-366.

HIRABAYASHIY, SUZKIN, TSUBOI M, ENDOTA, TOYODAT, SHINGAJ, KOSEKIH, VIDAL M, AND GOTOHY (2009). Polycomb limits the neurogenic competence of neural precursor cells to promote astrogenic fate transition. Neuron 63: 600-613.

IRINTCHEV A (2004). Structural and Functional Aberrations in the Cerebral Cortex of Tenascin-C Deficient Mice. Cerebral Cortex 15: 950-962.

JACOBS S, NATHWANI M, AND DOERING LC (2010). Fragile $X$ astrocytes induce developmental delays in dendrite maturation and synaptic protein expression. BMC Neurosci 11: 132.

KAGEYAMA R, OHTSUKA T, HATAKEYAMA J, AND OHSAWA R (2005). Roles of bHLH genes in neural stem cell differentiation. Exp Cell Res 306: 343-348.

KAKITA A, AND GOLDMAN JE (1999). Patterns and dynamics of SVZ cell migration in the postnatal forebrain: monitoring living progenitors in slice preparations. Neuron 23: 461-472.

KAKITAA, ZERLIN M, TAKAHASHIH, AND GOLDMAN JE (2003). Some glial progenitors in the neonatal subventricular zone migrate through the corpus callosum to the contralateral cerebral hemisphere. J Comp Neurol 458: 381-388.

KAMAKURA S, OISHI K, YOSHIMATSU T, NAKAFUKU M, MASUYAMA N, AND GOTOH Y (2004). Hes binding to STAT3 mediates crosstalk between Notch and JAK-STAT signalling. Nature Cell Biol 6: 547-554.

KANEKO N, MARÍN O, KOIKE M, HIROTA Y, UCHIYAMA Y, WU JY, LU Q, TESSIERLAVIGNE M, ALVAREZ-BUYLLA A, OKANO H, et al. (2010). New neurons clear the path of astrocytic processes for their rapid migration in the adult brain. Neuron 67: 213-223.

KAO HY, ORDENTLICH P, KOYANO-NAKAGAWA N, TANG Z, DOWNES M, KINTNER CR, EVANS RM, AND KADESCH T (1998). A histone deacetylase corepressor complex regulates the Notch signal transduction pathway. Genes Dev 12: 2269-2277.

KESSARIS N, FOGARTY M, IANNARELLI P, GRIST M, WEGNER M, AND RICHARDSON WD (2006). Competing waves of oligodendrocytes in the forebrain and postnatal elimination of an embryonic lineage. Nature Neurosci 9: 173-179.

KISHI Y, FUJII Y, HIRABAYASHI Y, AND GOTOH Y (2012). HMGA regulates the global chromatin state and neurogenic potential in neocortical precursor cells. Nature Neurosci 15(8): 1127-1133.

KNOEPFLER PS, ZHANG X, CHENG PF, GAFKEN PR, MCMAHON SB, AND EISENMAN RN (2006). Myc influences global chromatin structure. EMBO J 25: 2723-2734.

KOBLAR SA, TURNLEY AM, CLASSON BJ, REID KL, WARE CB, CHEEMA SS MURPHY M, AND BARTLETT PF (1998). Neural precursor differentiation into astrocytes requires signaling through the leukemia inhibitory factor receptor. Proc. Natl. Acad. Sci. USA 95: 3178-3181.

KORNBLUM HI, HUSSAIN R, WIESEN J, MIETTINEN P, ZURCHER SD, CHOW K, DERYNCK R, AND WERB Z (1998). Abnormal astrocyte development and neuronal death in mice lacking the epidermal growth factor receptor. $J$ Neurosci Res 53: 697-717.

KORNBLUM HI, YANNI DS, EASTERDAY MC, AND SEROOGY KB (2000). Expression of the EGF receptor family members ErbB2, ErbB3, and ErbB4 in germinal zones of the developing brain and in neurosphere cultures containing CNS stem cells. Dev Neurosci 22: 16-24.

KREBS DL, AND HILTON DJ (2001). SOCS proteins: negative regulators of cytokine signaling. Stem Cells 19: 378-387.

KRIEGSTEIN A, AND ALVAREZ-BUYLLA A (2009). The glial nature of embryonic and adult neural stem cells. Annu Rev Neurosci 32: 149-184.

KROHN K, ROZOVSKY I, WALS P, TETER B, ANDERSON CP, AND FINCH CE (1999). Glial fibrillary acidic protein transcription responses to transforming growth factor-beta1 and interleukin-1beta are mediated by a nuclear factor-1-like site in the near-upstream promoter. $J$ Neurochem 72: 1353-1361.

LEHMANN U, SCHMITZ J, WEISSENBACH M, SOBOTA RM, HORTNER M, FRIEDERICHS K, BEHRMANN I, TSIARIS W, SASAKI A, SCHNEIDER-MERGENER $\mathrm{J}$, et al. (2003). SHP2 and SOCS3 contribute to Tyr-759-dependent attenuation of interleukin-6 signaling through gp130. J Biol Chem 278: 661-671.

LEVISON SW, AND GOLDMAN JE (1993). Both oligodendrocytes and astrocytes develop from progenitors in the subventricular zone of postnatal rat forebrain. Neuron 10: 201-212.

LI X, NEWBERN JM, WU Y, MORGAN-SMITH M, ZHONG J, CHARRON J, AND SNIDER WD (2012). MEK Is a Key Regulator of Gliogenesis in the Developing Brain. Neuron 75: 1035-1050.

LILLIEN LE, SENDTNER M, ROHRER H, HUGHES SM, AND RAFF MC (1988). Type-2 astrocyte development in rat brain cultures is initiated by a CNTF-like protein produced by type-1 astrocytes. Neuron 1: 485-494.

LIU Y, HAN SSW, WU Y, TUOHY TMF, XUE H, CAI J, BACK SA, SHERMAN LS, FISCHERI, AND RAO MS (2004). CD44 expression identifies astrocyte-restricted precursor cells. Dev Biol 276: 31-46.

LUM M, TURBIC A, MITROVIC B, AND TURNLEY AM (2009). Fibroblast growth factor-9 inhibits astrocyte differentiation of adult mouse neural progenitor cells. J Neurosci Res 87: 2201-2210.

LUSKIN MB, AND MCDERMOTT K (1994). Divergent lineages for oligodendrocytes and astrocytes originating in the neonatal forebrain subventricular zone. Glia 11: $211-226$.

LUSKIN MB, PARNAVELAS JG, AND BARFIELD JA (1993). Neurons, astrocytes, and oligodendrocytes of the rat cerebral cortex originate from separate progenitor cells: an ultrastructural analysis of clonally related cells. J Neurosci 13: 1730-1750.

MAGAVI S, FRIEDMANN D, BANKS G, STOLFI A, AND LOIS C (2012). Coincident Generation of Pyramidal Neurons and Protoplasmic Astrocytes in Neocortical Columns. J Neurosci 32: 4762-4772.

MALATESTA P, AND GÖTZ M (2013). Radial glia - from boring cables to stem cell stars. Development 140: 483-486.

MALATESTA P, HARTFUSS E, AND GÖTZ M (2000). Isolation of radial glial cells by fluorescent-activated cell sorting reveals a neuronal lineage. Development 127: 5253-5263.

MALATESTA P, HACK MA, HARTFUSS E, KETTENMANN H, KLINKERT W, KIRCHHOFF F, AND GÖTZ M (2003). Neuronal or glial progeny: regional differences in radial glia fate. Neuron 37 : 751-764

MARSHALLCAG, SUZUKISO, AND GOLDMAN JE (2003). Gliogenic and neurogenic progenitors of the subventricular zone: who are they, where did they come from, and where are they going? Glia 43: 52-61.

MATSUMOTO S, BANINE F, STRUVE J, XING R, ADAMS C, LIU Y, METZGER D, CHAMBON P, RAO MS, AND SHERMAN LS (2006). Brg1 is required for murine neural stem cell maintenance and gliogenesis. Dev Biol 289: 372-383.

MAYER SI, ROSSLER OG, ENDO T, CHARNAY P, AND THIEL G (2009). Epidermalgrowth-factor-induced proliferation of astrocytes requires Egr transcription factors. J Cell Sci 122: 3340-3350.

MCCARTHYM, TURNBULLDH, WALSH CA, AND FISHELLG (2001). Telencephalic neural progenitors appear to be restricted to regional and glial fates before the onset of neurogenesis. J Neurosci 21: 6772-6781.

MEI L, AND XIONG W-C (2008). Neuregulin 1 in neural development, synaptic plasticity and schizophrenia. Nature Rev Neurosci 9: 437-452.

MÉNARD C, HEIN P, PAQUIN A, SAVELSON A, YANG XM, LEDERFEIN D, BARNABÉ-HEIDER F, MIR AA, STERNECK E, PETERSON AC, et al. (2002). An essential role for a MEK-C/EBP pathway during growth factor-regulated cortical neurogenesis. Neuron 36: 597-610.

MILLER MW (2003). Expression of transforming growth factor-beta in developing rat cerebral cortex: effects of prenatal exposure to ethanol. J Comp Neurol 460: 410-424.

MILLER FD, AND GAUTHIER AS (2007). Timing is everything: making neurons 
versus glia in the developing cortex. Neuron 54: 357-369.

MIN R, AND NEVIAN T (2012). Astrocyte signaling controls spike timing-dependent depression at neocortical synapses. Nature Neurosci 15: 746-753.

MINK S, HAENIG B, AND KLEMPNAUER KH (1997). Interaction and functional collaboration of p300 and C/EBPbeta. Mol Cell Biol 17: 6609-6617.

MORROW T, SONG MR, AND GHOSHA (2001). Sequential specification of neurons and glia by developmentally regulated extracellular factors. Development 128 : 3585-3594.

NAGAO M, CAMPBELL K, BURNS K, KUAN C-Y, TRUMPP A, AND NAKAFUKU M (2008). Coordinated control of self-renewal and differentiation of neural stem cells by Myc and the p19ARF-p53 pathway. J Cell Biol 183: 1243-1257.

NAKA H, NAKAMURA S, SHIMAZAKI T, AND OKANO H (2008). Requirement for COUP-TFI and II in the temporal specification of neural stem cells in CNS development. Nat Neurosci 11: 1014-1023.

NAKASHIMAK, YANAGISAWA M, ARAKAWA H, KIMURAN, HISATSUNE T, KAWABATA M, MIYAZONO K, AND TAGA T (1999a). Synergistic signaling in fetal brain by STAT3-Smad1 complex bridged by p300. Science 284: 479-482.

NAKASHIMAK, WIESES, YANAGISAWAM, ARAKAWAH, KIMURAN, HISATSUNET, YOSHIDAK, KISHIMOTOT, SENDTNERM, ANDTAGAT(1999b). Developmental requirement of gp130 signaling in neuronal survival and astrocyte differentiation. J Neurosci 19: 5429-5434.

NAKASHIMA K, YANAGISAWA M, ARAKAWA H, AND TAGA T (1999c). Astrocyte differentiation mediated by LIF in cooperation with BMP2. FEBS Lett 457: 43-46.

NAMIHIRA M, KOHYAMA J, SEMI K, SANOSAKA T, DENEEN B, TAGA T, AND NAKASHIMA K (2009). Committed neuronal precursors confer astrocytic potential on residual neural precursor cells. Dev Cell 16: 245-255.

NEDERGAARD M, RANSOMB, AND GOLDMANSA(2003). New roles for astrocytes: redefining the functional architecture of the brain. Trends Neurosci 26: 523-530.

NIETO M, SCHUURMANS C, BRITZ O, AND GUILLEMOT F (2001). Neural bHLH genes control the neuronal versus glial fate decision in cortical progenitors. Neuron 29: 401-413.

NOCTOR SC, MARTíNEZ-CERDEÑO V, IVIC L, AND KRIEGSTEIN AR (2004). Cortical neurons arise in symmetric and asymmetric division zones and migrate through specific phases. Nature Neurosci 7: 136-144.

OCHIAI W, YANAGISAWA M, TAKIZAWA T, NAKASHIMA K, AND TAGA T (2001). Astrocyte differentiation of fetal neuroepithelial cells involving cardiotrophin1-induced activation of STAT3. Cytokine 14: 264-271.

ONO K, TAKEBAYASHI H, IKEDA K, FURUSHO M, NISHIZAWA T, WATANABE K, AND IKENAKA K (2008). Regional- and temporal-dependent changes in the differentiation of Olig2 progenitors in the forebrain, and the impact on astrocyte development in the dorsal pallium. Dev Biol 320: 456-468.

PAQUIN A, BARNABÉ-HEIDER F, KAGEYAMA R, AND MILLER FD (2005). CCAAT/ enhancer-binding protein phosphorylation biases cortical precursors to generate neurons rather than astrocytes in vivo. J Neurosci 25: 10747-10758.

PEREIRA JD, SANSOM SN, SMITH J, DOBENECKER M-W, TARAKHOVSKY A, AND LIVESEY FJ (2010). Ezh2, the histone methyltransferase of PRC2, regulates the balance between self-renewal and differentiation in the cerebral cortex. Proc. Natl. Acad. Sci. USA 107: 15957-15962.

PIPER M, BARRY G, HAWKINS J, MASON S, LINDWALL C, LITTLE E, SARKAR A, SMITH AG, MOLDRICH RX, BOYLE GM, et al. (2010). NFIA controls telencephalic progenitor cell differentiation through repression of the Notch effector Hes1. J Neurosci 30: 9127-9139.

PREBIL M, JENSEN J, ZOREC R, AND KREFT M (2011). Astrocytes and energy metabolism. Arch Physiol Biochem 117: 64-69.

QIAN X, SHEN Q, GODERIE SK, HE W, CAPELA A, DAVIS AA, AND TEMPLE S (2000). Timing of CNS cell generation: a programmed sequence of neuron and glial cell production from isolated murine cortical stem cells. Neuron 28: 69-80.

RAFF MC, ABNEY ER, AND FOK-SEANG J (1985). Reconstitution of a developmental clock in vitro: a critical role for astrocytes in the timing of oligodendrocyte differentiation. Cell 42: 61-69.

RAJAN P, AND MCKAY RD (1998). Multiple routes to astrocytic differentiation in the CNS. J Neurosci 18: 3620-3629.

RAKIC P (1988). Specification of cerebral cortical areas. Science 241: 170-176.

RAO MS, NOBLE M, AND MAYER-PRÖSCHEL M (1998). A tripotential glial precursor cell is present in the developing spinal cord. Proc. Natl. Acad. Sci. USA 95:
3996-4001.

REID CB, LIANG I, AND WALSH C (1995). Systematic widespread clonal organization in cerebral cortex. Neuron 15: 299-310.

RIBONI L, VIANI P, BASSI R, GIUSSANI P, AND TETTAMANTI G (2001). Basic fibroblast growth factor-induced proliferation of primary astrocytes. evidence for the involvement of sphingomyelin biosynthesis. J Biol Chem 276: 12797-12804.

ROMERO-GRIMALDI C, MURILLO-CARRETERO M, LÓPEZ-TOLEDANO MA, CARRASCO M, CASTRO C, AND ESTRADAC (2011). ADAM-17/Tumor Necrosis Factor- $\alpha$-Converting Enzyme Inhibits Neurogenesis and Promotes Gliogenesis from Neural Stem Cells. Stem Cells 29: 1628-1639.

SAKAYORI N, KIKKAWAT, AND OSUMI N (2012). Reduced proliferation and excess astrogenesis of Pax6 heterozygous neural stem/progenitor cells. Neurosci Res 74: 116-121.

DE SAMPAIO E SPOHR TCL, MARTINEZ R, DA SILVA EF, NETO VM, AND GOMES FCA (2002). Neuro-glia interaction effects on GFAP gene: a novel role for transforming growth factor-beta1. Eur J Neurosci 16: 2059-2069.

SARDI SP, MURTIE J, KOIRALAS, PATTEN BA, AND CORFAS G (2006). Presenilindependent ErbB4 nuclear signaling regulates the timing of astrogenesis in the developing brain. Cell 127: 185-197.

SASAKI T, MATSUKI N, AND IKEGAYA Y (2011). Action-potential modulation during axonal conduction. Science 331: 599-601.

SCARDIGLIR (2003). Direct and concentration-dependent regulation of the proneural gene Neurogenin2 by Pax6. Development 130: 3269-3281.

SCHACHTRUP C, RYU JK, HELMRICK MJ, VAGENA E, GALANAKIS DK, DEGEN JL, MARGOLIS RU, AND AKASSOGLOU K (2010). Fibrinogen triggers astrocyte scar formation by promoting the availability of active TGF-beta after vascular damage. J Neurosci 30: 5843-5854.

SCHACHTRUP C, LE MOAN N, PASSINO MA, AND AKASSOGLOU K (2011). Hepatic stellate cells and astrocytes: Stars of scar formation and tissue repair. Cell Cycle 10: 1764-1771.

SCHEFFZEK K, AHMADIAN MR, KABSCH W, WIESMÜLLER L, LAUTWEIN A, SCHMITZ F, AND WITTINGHOFER A (1997). The Ras-RasGAP complex: structural basis for GTPase activation and its loss in oncogenic Ras mutants. Science 277: 333-338.

SCHMITZ J, WEISSENBACH M, HAAN S, HEINRICH PC, AND SCHAPER F (2000). SOCS3 exerts its inhibitory function on interleukin-6 signal transduction through the SHP2 recruitment site of gp130. J Biol Chem 275: 12848-12856.

SEUNTJENSE, NITYANANDAMA, MIQUELAJAUREGUIA, DEBRUYN J, STRYJEWSKAA, GOEBBELS S, NAVE K-A, HUYLEBROECKD, AND TARABYKIN V (2009). Sip1 regulates sequential fate decisions by feedback signaling from postmitotic neurons to progenitors. Nature Neurosci 12: 1373-1380.

SHIBUYA H, YAMAGUCHI K, SHIRAKABE K, TONEGAWAA, GOTOH Y, UENO N, IRIE K, NISHIDA E, AND MATSUMOTO K (1996). TAB1: an activator of the TAK1 MAPKKK in TGF-beta signal transduction. Science 272: 1179-1182.

SHIMOJO H, OHTSUKAT, AND KAGEYAMAR (2008). Oscillations in notch signaling regulate maintenance of neural progenitors. Neuron 58: 52-64.

SIBILIA M, STEINBACH JP, STINGL L, AGUZZI A, AND WAGNER EF (1998). A strain-independent postnatal neurodegeneration in mice lacking the EGF receptor. EMBO J 17: 719-731.

SILVER J, AND MILLER JH (2004). Regeneration beyond the glial scar. Nature Rev Neurosci 5: 146-156.

SONG M-R, AND GHOSH A (2004). FGF2-induced chromatin remodeling regulates CNTF-mediated gene expression and astrocyte differentiation. Nat Neurosci 7: 229-235.

STIPURSKY J, AND GOMES FCA (2007). TGF-beta1/SMAD signaling induces astrocyte fate commitment in vitro: implications for radial glia development. Glia 55: 1023-1033.

STRATHMANN FG, WANG X, AND MAYER-PRÖSCHEL M (2007). Identification of two novel glial-restricted cell populations in the embryonic telencephalon arising from unique origins. BMC Dev Biol 7: 33.

SUBRAMANIAN L, SARKARA, SHETTYAS, MURALIDHARAN B, PADMANABHAN $\mathrm{H}$, PIPER M, MONUKI ES, BACH I, GRONOSTAJSKI RM, RICHARDS LJ, et al. (2011). Transcription factor Lhx2 is necessary and sufficient to suppress astrogliogenesis and promote neurogenesis in the developing hippocampus. Proc. Natl. Acad. Sci. USA 108: E265-E274. 
SUN Y, NADAL-VICENS M, MISONO S, LIN MZ, ZUBIAGA A, HUA X, FAN G, AND GREENBERG ME (2001). Neurogenin promotes neurogenesis and inhibits glial differentiation by independent mechanisms. Cell 104: 365-376.

TAKIZAWAT, NAKASHIMAK, NAMIHIRAM, OCHIAIW, UEMURAA, YANAGISAWAM, FUJITAN, NAKAOM, ANDTAGAT (2001). DNAmethylation is a critical cell-intrinsic determinant of astrocyte differentiation in the fetal brain. Dev Cell 1: 749-758.

TAN S-L, NISHI M, OHTSUKA T, MATSUI T, TAKEMOTO K, KAMIO-MIURA A, ABURATANI H, SHINKAI Y, AND KAGEYAMA R (2012). Essential roles of the histone methyltransferase ESET in the epigenetic control of neural progenitor cells during development. Development 139: 3806-3816.

TAO-CHENG JH, NAGY Z, AND BRIGHTMAN MW (1987). Tight junctions of brain endothelium in vitro are enhanced by astroglia. J Neurosci 7: 3293-3299.

TEMPLE S, AND RAFF MC (1986). Clonal analysis of oligodendrocyte development in culture: evidence for a developmental clock that counts cell divisions. Cell 44: 773-779.

TSAI H-H, LI H, FUENTEALBA LC, MOLOFSKY AV, TAVEIRA-MARQUES R, ZHUANG H, TENNEY A, MURNEN AT, FANCY SPJ, MERKLE F, et al. (2012). Regional astrocyte allocation regulates CNS synaptogenesis and repair. Science 337: 358-362.

UEMURAA, TAKIZAWAT, OCHIAI W, YANAGISAWA M, NAKASHIMAK, AND TAGA $T$ (2002). Cardiotrophin-like cytokine induces astrocyte differentiation of fetal neuroepithelial cells via activation of STAT3. Cytokine 18: 1-7.

VALLEJO M (2009). PACAP signaling to DREAM: A cAMP-Dependent Pathway that Regulates Cortical Astrogliogenesis. Mol Neurobiol 39: 90-100.

VALLEJO I, AND VALLEJO M (2002). Pituitary adenylate cyclase-activating polypeptide induces astrocyte differentiation of precursor cells from developing cerebral cortex. Mol Cell Neurosci 21: 671-683.
VITI J, FEATHERS A, PHILLIPS J, AND LILLIEN L (2003). Epidermal growth factor receptors control competence to interpret leukemia inhibitory factor as an astrocyte inducer in developing cortex. J Neurosci 23: 3385-3393.

WALSHC, AND CEPKO CL (1992). Widespread dispersion of neuronal clones across functional regions of the cerebral cortex. Science 255: 434-440.

WALSH C, AND CEPKO CL (1993). Clonal dispersion in proliferative layers of developing cerebral cortex. Nature 362: 632-635.

WANG DD, AND BORDEY A (2008). The astrocyte odyssey. Prog Neurobiol 86 : 342-367.

WANG Y, KIM E, WANG X, NOVITCH BG, YOSHIKAWAK, CHANG L-S, AND ZHU Y (2012). ERK inhibition rescues defects in fate specification of Nf1-deficient neural progenitors and brain abnormalities. Cell 150: 816-830.

WEICKERT CS, AND BLUM M (1995). Striatal TGF-alpha: postnatal developmental expression and evidence for a role in the proliferation of subependymal cells. Brain Res Dev Brain Res 86: 203-216.

WILCZYNSKA KM, SINGH SK, ADAMS B, BRYAN L, RAO RR, VALERIE K, WRIGHT S, GRISWOLD-PRENNER I, AND KORDULA T (2009). Nuclear factor I isoforms regulate gene expression during the differentiation of human neural progenitors to astrocytes. Stem Cells 27: 1173-1181.

YOON K-J, KOO B-K, IM S-K, JEONG H-W, GHIM J, KWON M-C, MOON J-S, MIYATAT, AND KONG Y-Y (2008). Mind bomb 1-expressing intermediate progenitors generate notch signaling to maintain radial glial cells. Neuron 58: 519-531.

ZERLIN M, LEVISON SW, AND GOLDMAN JE (1995). Early patterns of migration, morphogenesis, and intermediate filament expression of subventricular zone cells in the postnatal rat forebrain. J Neurosci 15: 7238-7249.

ZHU X, BERGLES DE, AND NISHIYAMA A (2007). NG2 cells generate both oligodendrocytes and gray matter astrocytes. Development 135: 145-157. 


\section{Further Related Reading, published previously in the Int. J. Dev. Biol.}

Activated Notch1 is a stronger astrocytic stimulus than leukemia inhibitory factor for rat neural stem cells Nidia S. Rodríguez-Rivera, Anayansi Molina-Hernández, Erika Sánchez-Cruz, Diana Escalante-Alcalde and Iván Velasco Int. J. Dev. Biol. (2009) 53: 947-953

Contributions to Neuroembryology of Santiago Ramon y Cajal (1852-1934) and Jorge F. Tello (1880-1958) Luis Puelles

Int. J. Dev. Biol. (2009) 53: 1145-1160

Astroglia-microvessel relationship in the developing human telencephalon. D Virgintino, E Maiorano, M Errede, A Vimercati, P Greco, LSelvaggi, L Roncali and M Bertossi Int. J. Dev. Biol. (1998) 42: 1165-118

Development and organization of glial cells in Drosophila melanogaster. A Giangrande

Int. J. Dev. Biol. (1996) 40: 917-927

Early events in the histo- and cytogenesis of the vertebrate CNS.

J Nakai and S Fujita

Int. J. Dev. Biol. (1994) 38: 175-183

Developmental expression of neurofilament and glial filament proteins in rat cerebellum. L A Sawant, N N Hasgekar and L S Vyasarayani

Int. J. Dev. Biol. (1994) 38: 429-437

5 yr ISI Impact Factor $(2011)=2.959$
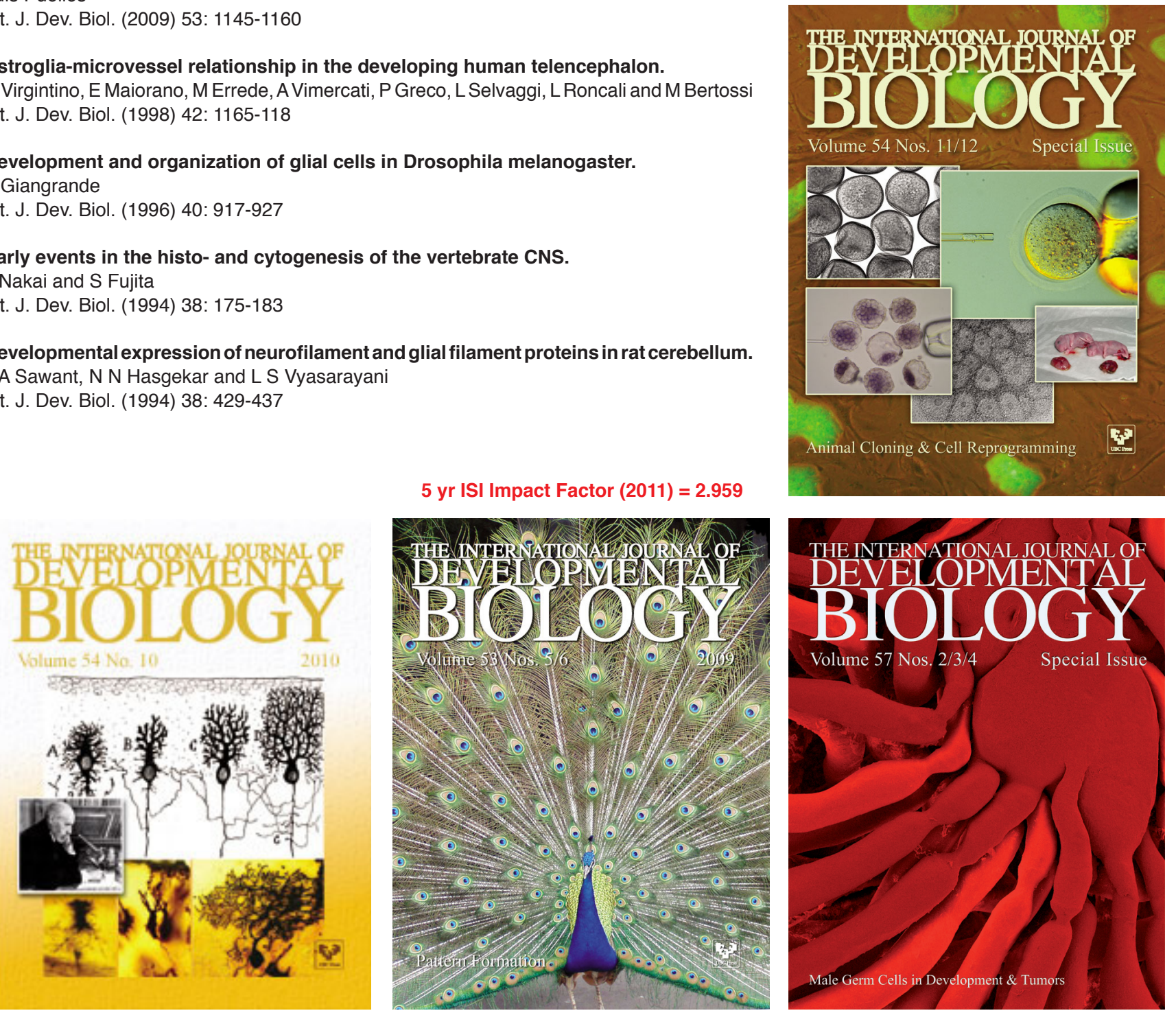